\title{
Spatial and temporal changes in the distribution of proteoglycans during
}

\section{avian neural crest development}

\author{
ROBERTO PERRIS $^{1, *}$, DANUTA KROTOSKI ${ }^{2}$, THOMAS LALLIER ${ }^{1}$, CARMEN DOMINGO $^{3}, \mathbf{J}$. \\ MICHAEL SORRELL ${ }^{4}$ and MARIANNE BRONNER-FRASER ${ }^{1}$ \\ ${ }^{1}$ Developmental Biology Center, University of California, Irvine, CA 92717, USA \\ ${ }^{2}$ National Institute of Child Health and Human Development, Execunve Plaza North, Room 643, 6130 Executive Blvd., Rockville, MD \\ 2085, USA \\ ${ }^{3}$ Department of Cell and Molecular Biology, University of California, Berkeley, CA 94720, USA \\ ${ }^{4}$ Department of Biology, Case Western Resenve University, Cleveland, OH 44106, USA \\ * Author for correspondence
}

\section{Summary}

In this study, we describe the distribution of various classes of proteoglycans and their potential matrix ligand, hyaluronan, during neural crest development in the trunk region of the chicken embryo. Different types of chondroitin and keratan sulfate proteoglycans were recognized using a panel of monoclonal antibodies produced against specific epitopes on their glycosaminoglycan chains. A heparan sulfate proteoglycan was identified by an antibody against its core protein. The distribution of hyaluronan was mapped using a biotinylated fragment that corresponds to the hyaluronanbinding region of cartilage proteoglycans. Four major patterns of proteoglycan immunoreactivity were observed. (1) Chondroitin-6-sulfate-rich proteoglycans and certain keratan sulfate proteoglycans were absent from regions containing migrating neural crest cells, but were present in interstitial matrices and basement membranes along prospective migratory pathways such as the ventral portion of the sclerotome. Although initially distributed uniformly along the rostrocaudal extent of the sclerotome, these proteoglycans became rearranged to the caudal portion of the sclerotome with progressive migration of neural crest cells through the rostral sclerotome and their aggregation into peripheral ganglia. (2) A subset of chondroitin/keratan sulfate proteoglycans bearing primarily unsulfated chondroitin chains was observed exclusively in regions where neural crest cells were absent or delayed from entering, such as the perinotochordal and subepidermal spaces. (3) A subset of chondroitin/keratan sulfate proteoglycans was restricted to the perinotochordal region and, following gangliogenesis, was arranged in a metameric pattern corresponding to the sites where presumptive vertebral arches form. (4) Certain keratan sulfate proteoglycans and a heparan sulfate proteoglycan were observed in basement membranes and in an interstitial matrix uniformly distributed along the rostrocaudal extent of the sclerotome. After gangliogenesis, the neural crestderived dorsal root and sympathetic ganglia contained both these proteoglycan types, but were essentially free of other chondroitin/keratan-proteoglycan subsets. Hyaluronan generally colocalized with the first set of proteoglycans, but also was concentrated around migrating neural crest cells and was reduced in neural crest-derived ganglia. These observations demonstrate that proteoglycans have diverse and dynamic distributions during times of neural crest development and chondrogenesis of the presumptive vertebrae. In general, chondroitin/keratan sulfate proteoglycans are abundant in regions where neural crest cells are absent, and their segmental distribution inversely correlates with that of neural crest-derived ganglia.

Key words: proteoglycans, hyaluronan, neural crest, avian embryo, cell migration, extracellular matrix.

\section{Introduction}

Neural crest cells migrate long distances along pathways containing an intricate extracellular matrix (ECM). As a consequence, the ECM is thought to play a central role in several aspects of neural crest development. In vitro, neural crest cells migrate avidly on numerous
ECM molecules including fibronectin, laminin and collagens (Newgreen and Erickson, 1986; Perris and Johansson, 1987; Perris et al. 1989; Perris et al. 1990a), suggesting that individual matrix components may serve as permissive migratory substrates. Ultrastructural studies performed in situ reveal that neural crest cells form specialized contacts with this fibrillar matrix 
network encountered during migration (Löfberg et al. 1980; Newgreen and Erickson, 1986; Perris et al. $1990 \mathrm{~b}$ ). In ovo injections of antibodies against individual matrix molecules or their cell surface receptors results in abnormal neural crest development in vivo (Bronner-Fraser, 1985, 1986a; Bronner-Fraser and Lallier, 1988; Bronner-Fraser, 1988). Moreover, transplantations of regionally and temporally defined matrices adsorbed onto membrane microcarriers have provided evidence that the ECM can prematurely promote the onset of neural crest cell movement in vivo (Löfberg et al. 1985, 1988).

A logical first step in establishing the role of the ECM in neural crest cell migration is to determine its structural and molecular composition at various phases of neural crest development. Ultrastructural and immunohistochemical studies have revealed that the interstitial matrix along trunk neural crest migratory pathways consists of a fibrillar collagenous network, which contains abundant amounts of fibronectin, tenascin/cytotactin and glycosaminoglycans (Newgreen and Erickson, 1986; Perris and Bronner-Fraser, 1989; Perris et al. 1990a; Newgreen et al. 1986, 1990). Basement membrane matrices, enriched in laminin and collagen type IV, also line some neural crest migratory routes (Newgreen and Erickson, 1986; Perris and Bronner-Fraser, 1989; Perris et al. 1990b).

Although a great deal of information has been compiled regarding the distribution and possible function of cell adhesion glycoproteins such as fibronectin, laminin, cytotactin/tenascin and various collagens during neural crest cell migration, far less is known about the role of proteoglycans in this process. Proteoglycans represent a heterogeneous population of molecules that contribute to the compositional diversity of the ECM. Indirect evidence that proteoglycans might be well-represented during neural crest development has emerged from a series of histochemical studies using cationic dyes, in situ metabolic labelling and differential enzymatic degradation (Kvist and Finnegan, 1970; Pintar, 1978; Löfberg et al. 1980; Newgreen et al. 1982, 1986; Perris et al. 1990b). From these observations it was concluded that several distinct families of matrix and cell-associated proteoglycans were expressed at various phases of neural crest development. However, the nature and spatiotemporal distribution of specific populations of proteoglycans present at these early stages of development, as well as their relationship to their potential ligands, such as collagens and hyaluronan, has not been determined.

In this study, we have examined the distribution of various proteoglycan subclasses in situ and have determined their spatial and temporal organization relative to the development of the trunk neural crest in the chick embryo. For this purpose, a panel of monoclonal antibodies that specifically detect native carbohydrate structures of chick proteoglycans were used in combination with differential enzymatic degradation and antibodies generated against chondroitinase-digested murine proteoglycans. In addition, a specific probe for hyaluronan (Knudsen and Toole,
1985; Ripellino et al. 1985) was used to map the distribution of this potential matrix and cell surfaceassociated ligand for proteoglycans. Our observations indicate that a time-related and region-specific organization of diverse types of proteoglycans occurs during neural crest cell migration and gangliogenesis, and the onset of vertebral chondrogenesis.

\section{Materials and methods}

Production and screening of monoclonal antibodies $(m A b s)$ against chondroitin $(C S)$ and keratan sulfate (KS) chains of proteoglycans (PGs)

Native CS/KS-PG monomers were extracted from bone marrow of femurs and tibias of 17 day old chick embryos using $4 \mathrm{M}$ guanidine- $\mathrm{HCl}$ in the presence of protease inhibitors as previously described (Oegema et al. 1975; Sorrell et al. 1988). Solid $\mathrm{CsCl}$ was added to the extract to give the final density of $1.5 \mathrm{~g} \mathrm{ml}^{-1}$, and the solution was centrifuged at $100000 \mathrm{~g}$ for $48 \mathrm{~h}$. The bottom one third of the gradient, with the density of $1.6 \mathrm{~g} \mathrm{ml}^{-1}$, was collected, dialyzed against $0.15 \mathrm{M} \mathrm{NaCl}$, then water and lyophilized as previously described (Sorrell et al. 1988). The purified, high buoyant density PGs (D1 fraction), which have been shown to be substituted with both CS and KS chains, were then used to immunize mice. The immunization protocol and the protocol for the production of hybridoma were as previously published (Caterson et al. 1987; Sorrell et al. 1990). Clones resulting from the fusion were tested in ELISA for the presence of antibodies that recognized the marrow PGs as well as PGs from other sources. Antibodies produced by nine such clones, 7D4, 6C3, 4C3, 4D3, 3D2, $1 B 4,4 D 1,2 D 3$ and 8C2, were identified and classified as IgM kappa. Each clone was then subcloned and used to produce ascites fluid. The ascites fluid was further screened for the ability of the antibody to identify epitopes on a number of different purified CS/KS-PG monomers, in their intact form or after alternative digestion with chondroitinase $A B C$ and keratanase (see below).

\section{Other antibodies}

MAbs 2B6, 1B5, 3B3 and 5D4 were obtained from Dr Bruce Caterson, Division of Orthopaedics, Department of Surgery, University of North Carolina, Chapel Hill, NC. The mAb $33-2$, kindly provided by Dr Douglas Fambrough (The John Hopkins University, Baltimore, MA), reacts with a core protein-associated epitope located on a large molecular mass HS-PG $\left(\mathrm{MW}>300 \times 10^{3} M_{\mathrm{r}}\right)$ of embryonic chick skeletal muscle (Bayne et al. 1984). The HNK-1 antibody was purified from ascites fluid (American Tissue Culture, Inc) by column chromatography on protamine sulfate followed by ammonium sulfate precipitation. In some cases, the purified HNK-1 antibody was biotinylated using biotin- $N$-hydroxysuccinamide ester (Calbiochem) according to a previously published procedure (Perris and Johansson, 1987; Perris et al. 1989).

\section{ELISA}

Proteoglycan monomers from shark cranial cartilage (A1), embryonic chick epiphysial cartilage (D1), bovine articular cartilage (A1D1) bovine nasal cartilage (A1D1) and Swarm rat chondrosarcoma (A1D1) were purified according to previously published procedures (Oegema et al. 1975; Sorrell et al. 1988, 1990). Wells of microtiter plates (Costar half area plates) were coated with PG monomers $25-50 \mu \mathrm{g} \mathrm{ml}^{-1}$ (dry weight) in PBS overnight at $4^{\circ} \mathrm{C}$. Proteoglycan-free areas of the wells were then blocked with $1 \% \mathrm{BSA}(\mathrm{v} / \mathrm{w})$ in PBS for 
$1-2 \mathrm{~h}$ at $37^{\circ} \mathrm{C}$. In some experiments, wells with immobilized PGs were digested for $5 \mathrm{~min}$ at room temperature with $10 \mu$ i.u. ml $\mathrm{m}^{-1}-100 \mathrm{mi} . \mathrm{u} . \mathrm{ml}^{-1}$ chondroitinase ABC (Sigma), or 70 mi.u. $\mathrm{ml}^{-1}$ Pseudomonas endo- $\beta$-galactosidase (keratanase; ICN Biochemicals Inc.), dissolved in Tris- $\mathrm{HCl}$ buffer, $\mathrm{pH} 7.6$, containing protease inhibitors and $1 \%$ BSA. Digested and untreated proteoglycan-coated wells were extensively rinsed with cold PBS and incubated with the various mAbs (1:100-1:700000) diluted in PBS for $1 \mathrm{~h}$ at $37^{\circ} \mathrm{C}$, followed by sequential incubation with horseradish peroxidase-conjugated goat anti-mouse Ig (Southern Biotechnology) diluted $1: 500$ in $0.1 \mathrm{M}$ Tris $-0.9 \% \mathrm{NaCl} \mathrm{pH} 7.6$ for $1 \mathrm{~h}$ at $37^{\circ} \mathrm{C}$, and 0 -phenylenediamine $\left(0.4 \mathrm{mg} \mathrm{m}^{-1}\right) / \mathrm{H}_{2} \mathrm{O}_{2}$ $(0.0015 \%)$. The enzyme reaction was stopped by addition of $2 \mathrm{M} \mathrm{H}_{2} \mathrm{SO}_{4}$ and the adsorbance readings were performed at $492 \mathrm{~nm}$ in a Bio-Rad microplate reader. Competitive ELISA was carried out by coating microwell plates with $50 \mu \mathrm{g} \mathrm{ml}^{-1}$ monomers of shark cranial cartilage proteoglycan as indicated above. Serial $50 \%$ dilutions of shark cranial cartilage, chick bone marrow, chick epiphysial cartilage, bovine articular cartilage or bovine nasal cartilage were prepared in PBS with $1 \%$ BSA. Equal aliquots of diluted antigen, or buffer alone, were added to a constant volume of antibody $(6 \mathrm{C} 3$ diluted $1: 25000 ; 7 \mathrm{D} 4$ diluted $1: 150000 ; 4 \mathrm{C} 3$ diluted $1: 6000)$ in the same buffer, incubated at $37^{\circ} \mathrm{C}$ for $1 \mathrm{~h}$, and then added to the coated wells. Standard ELISA was performed as above. The $\%$ inhibition was determined for three assays, averaged and plotted versus $\mu \mathrm{g} \mathrm{ml}^{-1}$ of competing antigen. The amount of competing antigen required to give $50 \%$ inhibition was then obtained by extrapolation from the inhibition curves.

\section{Preparation of the hyaluronan probe}

A $65 \times 10^{3} M_{\mathrm{r}}$ proteolytic fragment corresponding to the hyaluronan-binding region of the bovine nasal cartilage proteoglycan was generously provided by $\mathrm{Dr}$ Torward Laurent (Department of Medical and Physiological Chemistry, Biomedical Center, Uppsala, Sweden). The fragment was generated by affinity chromatography as previously described (Tengblad, 1979; Laurent and Tengblad, 1980). The PG fragment, with attached low molecular weight hyaluronan (16-30 oligosaccharides) to preserve the hyaluronan-binding activity, was biotinylated according to the same procedure as indicated for the HNK-1 antibody. Purified hyaluronan (human umbilical cord; $M_{\mathrm{r}} 1000000$; Sigma) was bound to AH-Sepharose 4B (Pharmacia) as described by Tengblad (1979). Before use, the biotinylated hyaluronan-binding fragment was then dissociated from the hyaluronan oligosaccharides by transfer to a $4 \mathrm{~m}$ guanidine- $\mathrm{HCl}-50 \mathrm{~mm}$ sodium acetate buffer, pH5.8, containing $10 \mathrm{~mm}$ EDTA, $100 \mathrm{~mm}$ 6-aminohexanoic acid, $5 \mathrm{~mm}$ benzamidine hydrochloride, and $2 \mathrm{~mm}$ phenylmethylsulfonyl fluoride (PSMF; Sigma).

\section{Preparation of tissues for immunohistochemistry}

Chick embryos at developmental stages 14-23 were rapidly frozen in liquid nitrogen-cooled isopentane and immediately transferred to methanol precooled to $-80^{\circ} \mathrm{C}$ and stored at this temperature for 3 days. They were then successively transferred to $-35^{\circ} \mathrm{C}$ for 1 day, $-20^{\circ} \mathrm{C}$ for 2 days and $4^{\circ} \mathrm{C}$ for 2 days. Following cryofixation, embryos were embedded in paraplast after one change of methanol:histosol $(7: 3)$, one change of methanol:histosol (3:7), two changes of histosol, one change of histosol:paraplast (1:1), and three changes of paraplast at $20 \mathrm{~min}$ for each step. A number of other procedures, including direct fixation in modified Karnovsky's fixative, $4 \%$ paraformaldehyde, Sainte-Marie, periodatelysine-paraformaldehyde and Zenker's fixatives followed by paraplast embedding or cryosectioning were also tested and were found to be significantly less efficient in retaining reactivity for the various anti-proteoglycan mAbs. One exception was the mAb 33-2 (anti-HS-PG antibody) for which optimal preservation of immunoreactivity was obtained after methanol fixation and cryosectioning. The latter was accomplished according to previously published procedures (Krotoski et al. 1986). Serial transverse, horizontal and parasagittal sections through the mid-trunk level of the embryo were cut at $10-20 \mu \mathrm{m}$ and mounted on gelatinized or albuminized slides.

\section{Enzymatic pre-digestions of tissue sections}

In cases where antibody application was preceded by enzymatic digestion, sections were incubated with the various enzymes for $1-3 \mathrm{~h}$ at $37^{\circ} \mathrm{C}$. Streptomyces hyaluronidase (Sigma) was used at $115 \mathrm{i} . \mathrm{u} . \mathrm{ml}^{-1}$ in $0.1 \mathrm{M}$ sodium acetate buffer, pH5.2, containing $250 \mu \mathrm{g} \mathrm{ml}^{-1}$ ovomucoid (trypsin inhibitor O-IV), 1 mм PMSF, $1 \mathrm{~mm}$ EDTA, $1 \mathrm{~mm}$ iodoacetidamine and $200 \mathrm{Ki} . u$. $\mathrm{ml}^{-1}$ aprotonin (all Sigma). Chondroitinases $\mathrm{ABC}$ and $\mathrm{AC}$ II (Sigma) were used at $0.2 \mathrm{i} . \mathrm{u} . \mathrm{ml}^{-1}$ in $0.1 \mathrm{M}$ bicine buffer (Calbiochem), pH 8.0, containing $0.1 \%$ BSA. Keratanase (Pseudomonas sp. IFO 13309) and endo- $\beta$ galactosidase (Escherichia freundii; ICN Biochemicals Inc.) were applied at 0.01 i.u. $\mathrm{ml}^{-1}$ in $50 \mathrm{~mm}$ Tris- $\mathrm{HCl}$ buffer $\mathrm{pH} 7.2$, containing $80 \mathrm{~mm} \mathrm{NaCl}, 1 \mathrm{~mm}$ EDTA, 1 mm iodoacetamide, $1 \mathrm{~mm}$ PSMF, and $5 \mu \mathrm{g} \mathrm{ml}^{-1}$ pepstatin A (Sigma).

\section{Immunohistochemistry}

Incubation with primary antibodies (1:50-1:150 in $0.01 \mathrm{~m}$ phosphate buffer, $\mathrm{pH} 7.2$, containing $0.1 \% \mathrm{BSA}$ ) was carried out overnight at $4^{\circ} \mathrm{C}$, except for the $\mathrm{HNK}-1$ labelling that was performed for $2 \mathrm{~h}$ at room temperature. Antibody-antigen binding was visualized by indirect immunofluorescence using Ig-class and species specific secondary antibodies, directly conjugated to fluorescein, or rhodamine (Zymed Laboratories). Double labelling was performed using biotinylated HNK-1 antibody, visualized by incubation of the sections with streptavidin-Texas Red complexes (1:200; Amersham). Labelled sections were mounted in glycerol-Tris- $\mathrm{HCl}$ buffer, pH 8.0, containing $2 \mathrm{mg} \mathrm{ml}^{-1} 1,4$-diazabicyclo $(2,2,2$, octane. In some cases, comparative stainings with anti-PG antibodies and the HNK-1 antibody were carried out on adjacent sections to avoid possible steric hindrance effects of $\operatorname{lgM}$ antibodies.

\section{Detection of hyaluronan in tissue sections}

Stage 14-23 embryos were fixed in phosphate-buffered $4 \%$ paraformaldehyde, $\mathrm{pH} 7.2$, containing $0.5 \%$ cetylpyrinidium chloride and $0.1 \%$ polyvinylpyrrolidone $\left(M_{\mathrm{r}} 40000 ;\right.$ Sigma $)$ for $12-18$ h at 4 (Derby and Pintar, 1978). Fixed embryos were rinsed, embedded in gelatin and sectioned as described above. Tissue sections were incubated with $30-100 \mu \mathrm{g}$ biotinylated hyaluronan probe in $0.1 \mathrm{~m}$ phosphate-buffered saline, $\mathrm{pH} 7.2$, at $4^{\circ} \mathrm{C}$ overnight. Sections were then extensively rinsed in buffer containing $0.01 \%$ Nonidet P-40, incubated with streptavidin-fluorescein and finally mounted as described for antibody-labelled sections. Control sections were predigested with Streptomyces hyaluronidase (Sigma) in the presence of protease inhibitors (see above), or incubated with inactivated probe. For the latter purpose, the biotinylated hyaluronan-binding fragment was preincubated with a molar excess $\left(100 \mu \mathrm{g} \mathrm{m}^{-1}\right)$ of hyaluronan oligosaccharides (16-30) for $1 \mathrm{~h}$ at $37^{\circ} \mathrm{C}$, dialyzed to remove excess nonbound oligosaccharides, and then applied to the sections. In some cases, sections were double-labelled with the hyaluronan probe and the HNK-1 antibody. 


\section{Confocal laser microscopy}

In a number of cases, stained sections were analyzed by confocal laser microscopy in conjunction with computerized image analysis. For this purpose, we used a Bio-Rad MRC 500 laser unit attached to an epifluorescent microscope (Nikon, Labphot), a videoprinter VP 3500 (Seikosha), a 3D6 personal computer, and Bio-Rad software for image analysis. Relative staining intensities were analyzed according to an arbitrary value scale of $0-255$ in a series of 74 transversal sections cut between somite 15 and 22 of stage 17 embryos (29-31 somites) and stained with $\mathrm{mAb} 4 \mathrm{C} 3$; and a series of 16 horizontal sections spanning $>20$ somites of similar age embryos stained with $\mathrm{mAb}$ 7D4. Transverse sections were analyzed in the medial-lateral plane by single spot measurements across their dorsal portion, starting and ending in the subepidermal space. A single spot measurement was also taken within cells of the neural tube where no immunoreactivity was observed and was used to correct for the background nonspecific fluorescence. Analysis in the dorsal-ventral dimension was carried out by consecutive single spot measurements along an arbitrary vertical line drawn across the section and passing through the subepidermal space, the lateral sclerotome, the perichordal area and finally the periaortic area. Horizontal sections containing the mid-portion of the neural tube were analyzed in the rostral-caudal dimension by recurring spot measurements at the borders and center of each somite, and within the intersomitic clefts, starting from the most recently formed somite and progressing rostrally. In this case, control values for correction of the nonspecific background fluorescence were obtained from the dermamyotome, which consistently lacked proteoglycan immunoreactivity.

\section{Specificity of the anti-chondroitin/keratan sulfate $m A b s$}

The characteristics and specificities of the various $m A b s$ are summarized in Table 1. Immunization of mice with high buoyant density PGs extracted from bone marrow of 17 days old chick embryos resulted in nine clones producing $\mathrm{mAbs}$ specific for CS and KS glycosaminoglycans. MAbs 7D4, 6C3, $4 \mathrm{D} 3$ and $4 \mathrm{C} 3$ all reacted with epitopes expressed on native $C S$ moieties of cartilage PGs from a variety of sources including chick epiphysis, bovine arteries and nose, chick bone marrow and shark cranium (Fig. 1). Although all five mAbs detected epitopes on CS-PGs, direct and competitive ELISA using five distinct PG types as model antigens clearly demonstrated that each antibody detected a different structural element (Fig. 1A). ELISA also showed that, while the antigenic profiles of the chick CS-PGs were related, the antigenic profiles of the other CS-PGs were characteristic for each type. Combined use of ELISA and chondroitinase $A B C$ digestion proved that the immunological diversity resided in the $C S$ chains. Specific épitopes were differentially removed by various concentrations of enzyme (Fig. 1B), consistent with the idea that each of these antibodies recognized a unique structural unit. For example, the epitope recognized by $\mathrm{mAb}$ 6C3 was ten-fold more sensitive to digestion than those recognized by $7 \mathrm{D} 4$ or $4 \mathrm{C} 3$. Recent data indicate that mAbs 7D4, 6C3 and 4C3 primarily recognize CS chains with prevalent 6-sulfated groups, whereas mAb 4D3 seems to react primarily with 4-sulfated chondroitins (Sorrell, unpublished).

MAbs 4D1, 3D2, 1B4, 8C2 and 5D4 also recognized epitopes on CS-PG monomers, but unlike the five mAbs described above, these epitopes were not removed by chondroitinase predigestion of the antigens. In fact, antigenicity of PGs for the latter mAbs sometimes increases following chondroitinase treatment (data not shown). In
Table 1. Specificity and characteristics of the various $m A b s$

\begin{tabular}{|c|c|c|c|}
\hline Antibody & Antigen & Reactivity & Epitope \\
\hline 7D4 & CS-PG & native $C S$ & unknown \\
\hline $6 \mathrm{C} 3$ & CS-PG & native CS & unknown \\
\hline $4 \mathrm{C3}$ & $\mathrm{CS} \cdot \mathrm{PG}$ & native $C S$ & unknown \\
\hline 4D3 & CS-PG & native $\mathrm{CS}$ & unknown \\
\hline $3 B 3$ & CS-PG & Ch6S & GlcUA-6SO $4, N$-AcGal \\
\hline $1 \mathrm{~B} 5$ & CS-PG & Cho & GlcUA, $N$-AcGal/Glu \\
\hline 2B6 & $\mathrm{CS}-\mathrm{PG}$ & Ch4S/DS & GlcUA-4SO ${ }_{4}, N$-AcGal \\
\hline 4D1 & (CS)/KS-PG & native $\mathrm{KS}$ & unknown \\
\hline 3D2 & $(\mathrm{CS}) / \mathrm{KS}-\mathrm{PG}$ & native $\mathrm{KS}$ & unknown \\
\hline $8 \mathrm{C} 2$ & $(\mathrm{CS}) / \mathrm{KS}-\mathrm{PG}$ & native $\mathrm{KS}$ & unknown \\
\hline 5D4 & $(\mathrm{CS}) / \mathrm{KS}-\mathrm{PG}$ & native $\mathrm{KS}$ & $(N-\mathrm{AcLac})_{\mathrm{n} \geq 6}, \mathrm{SO}_{4}$ \\
\hline $33-2$ & HS-PG & $>300 \mathrm{kD} \mathrm{CP}$ & unknown \\
\hline
\end{tabular}

Note: The epitopes recognized by mAbs 1B5, 3B3 and 2B6 are generated by chondroitinase $\mathrm{ABC} / \mathrm{AC}$ II digestion (Couchman et al. 1984; Caterson et al. 1987), which involves an elimination reaction introducing a 4,5-delta unsaturation of the GlcUA moiety of glycosaminoglycan disaccharides. The epitope recognized by $\mathrm{mAb} 5 \mathrm{D} 4$ comprises a miminum of six sugar units in linear nonsubstituted sulfated poly-( $N$-acetyllactosamine $)$ structures of $\mathrm{KS}$ (Mehmet et al. 1986; Caterson et al. 1987). mAb 2B6 has a dual reactivity for both Ch4S and DS chains substituted on proteoglycan core proteins. Its specificity is determined by chondroitinase $\mathrm{ABC}$ or $\mathrm{AC}$ II digestion prior to immunostaining. Following chondroitinase $\mathrm{ABC}$ digestion the $\mathrm{mAb}$ recognizes both Ch4S and DS, whereas following chondroitinase AC II digestion it reacts only with Ch4S. The mAb $3 B 3$ also detects an unidentified epitope on mature chick cartilage proteoglycans that is not generated by chondroitinase digestion (Sorrell et al 1990). GlcUA glucuronic acid; $N$-AcGal/Glu, $N$-Acetylgalactosamine/ glucosamine; $N$-AcLac, $N$-Acetyllactosamine; CP, core protein.

contrast, digestion of immobilized embryonic chick cartilage CS-PG abolished virtually all immunoreactivity for these mAbs (Fig. 1C). The moderate reduction in immunoreactivity for bovine nasal cartilage CS-PG is likely to be due to differences in the structure of the KS chains of these two species-specific PGs.

The overall staining patterns obtained with $\mathrm{mAbs} 7 \mathrm{D} 4,6 \mathrm{C} 3$ and $4 \mathrm{C} 3$ were similar and therefore are described collectively. However, the extent and intensity of the labelling obtained with these mAbs decreased in the order $4 \mathrm{C} 3>7 \mathrm{D} 4>6 \mathrm{C} 3$, even though mAb 7D4 reacted 15 times more strongly with isolated chick proteoglycans than mAb 4C3 (Fig. 1A). Minor differences in the immunoreactive patterns obtained with these mAbs were also observed within the sclerotome and in the perinotochordal area.

\section{Results}

Analysis of the distribution of proteoglycans (PGs) and hyaluronan was carried out in the mid-trunk region at two developmental stages: during neural crest cell migration (stages 14-19 at level of somites 12-27; Fig. 2A) and following gangliogenesis (stages 21-23 between wing and limb buds). Four generalized patterns of immunoreactivity were distinguishable and those will be referred to as patterns I-IV (Table 2).

Distribution of chondroitin sulfate proteoglycans (CSPGs)

During neural crest cell migration (stages 14-19)

Proteoglycans detected by the mAbs 7D4/6C3/4C3 

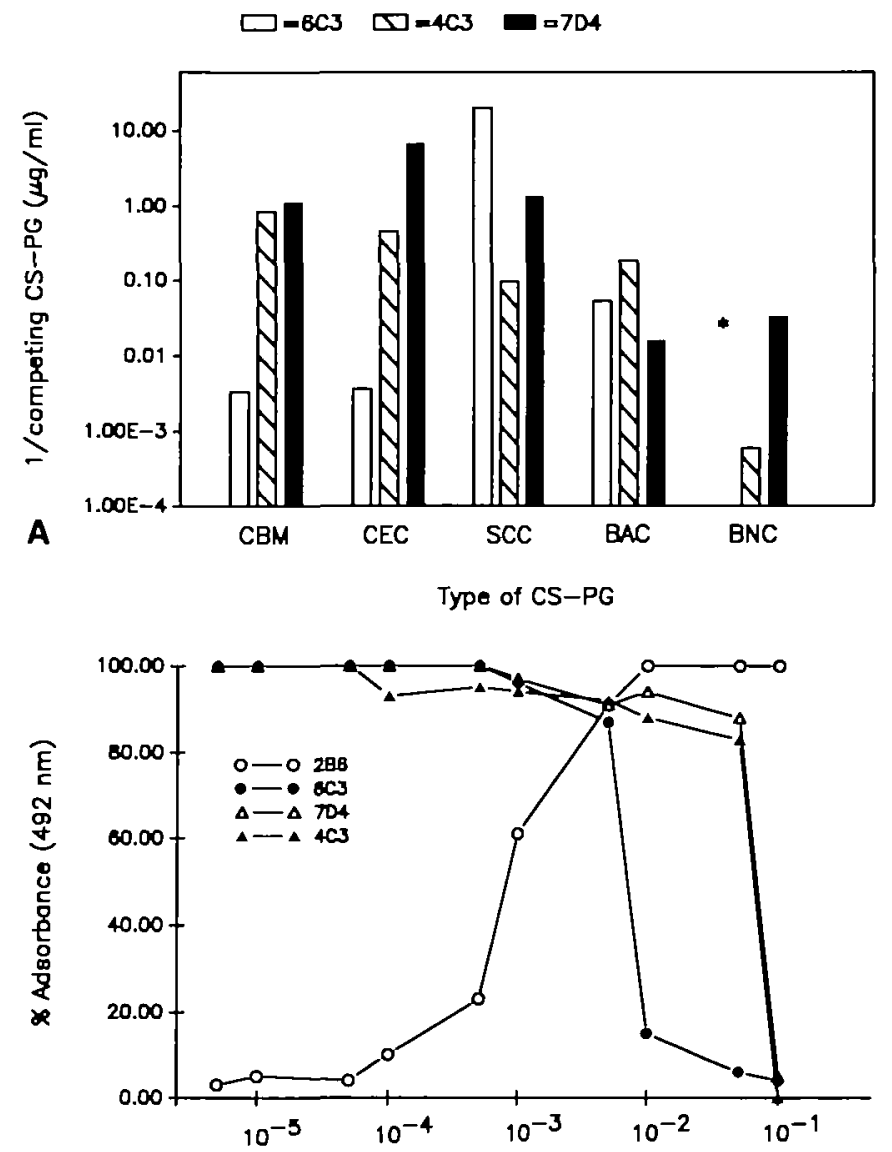

B

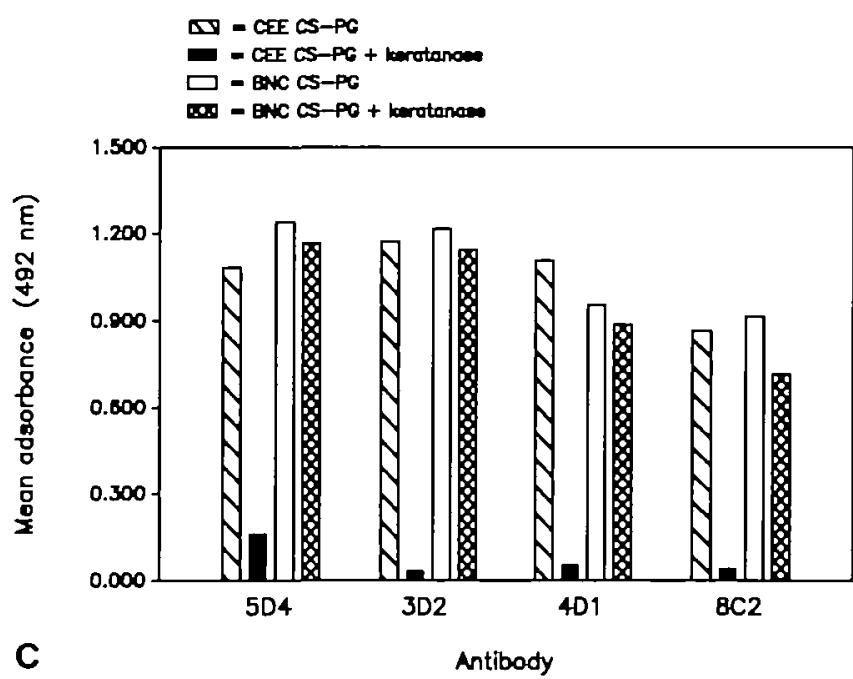

were distributed widely along neural crest cell migratory pathways. The immunostaining patterns produced by antibodies 7D4/6C3/4C3 (Fig. 2B) were similar to that of $\mathrm{mAb} 3 \mathrm{~B} 3$, which recognizes chondroitin-6-sulfate (Ch6S) moieties following chondroitinase $\mathrm{ABC}$ digestion. Thus, it is possible that the native epitopes recognized by these antibodies were expressed on CS chains rich in 6-sulfated groups. This staining pattern will be refered to as pattern I (Table 2). At initial stages of neural crest cell migration, pattern I CSPGs were detected within the subepidermal basement
Fig. 1. (A) Competitive ELISA using shark cranial cartilage (SCC) proteoglycan as an immobilized antigen and chick bone marrow (CBM), $\mathrm{CEE}$, bovine articular cartilage (BAC) and BNC protoglycan monomers as competing antigens. Values denote means of the amount of competing proteoglycan yielding $50 \%$ inhibition of the antibody-antigen binding. The values are expressed as $1 /$ amount of competing proteoglycan and hence a high value indicates that the proteoglycan was an efficient competitor of the antibody-antigen binding. MAb $6 \mathrm{C} 3$ recognizes an epitope on BNC CS-PG, but $50 \%$ inhibition level was not reached using up to $1000 \mu \mathrm{g} \mathrm{ml}^{-1}$ competing antigen $(*)$. Because of its low affinity for SCC proteoglycan, mAb 4D3 could not be tested in this assay. (B) Concentration-dependent effects of chondroitinase ABC digestion of immobilized CEE proteoglycan monomers on the binding of the various mAbs. MAb 2B6 was used as a control for the efficiency of the enzymatic degradation, since digestion with chondroitinase $A B C$ is required to generate the epitope recognized by this antibody (see Table I). The data indicate that CS chains are degraded at enzyme concentrations higher than $10^{-4}$ i.u. $\mathrm{ml}^{-1}$. Note that the epitopes recognized by mAbs $6 \mathrm{C} 3,4 \mathrm{C} 3$ and $7 \mathrm{D} 4$ are totally removed by the chondroitinase digestion, but only by enzyme concentrations considerably higher than those needed to generate the 2B6 epitope. Each point corresponds to \% values of the maximal adsorbance readings from triplicate tests. (D) Differential elimination of antibody reactivity following keratanase digestion of CEE and BNC proteoglycan monomers (mean values of maximal adsorbance). The differential reduction in antigenicity seen for CEE versus BNC CS-PG reflects the inability of keratanase to digest equally all forms of KS.

Table 2. Generalized patterns of $P G$ distribution during neural crest development

\begin{tabular}{lll}
\hline \multicolumn{1}{c}{ Pattern } & Antigens & \multicolumn{1}{c}{ Antibodies } \\
\hline I & CS-PG & 7D4, 6C3, 4C3 \\
& Ch6S-PG & 3B3 \\
II & KS-PG & 5D4 \\
& Ch0-PG & 1B5 \\
III & KS-PG & $4 \mathrm{D} 1,1 \mathrm{~B} 4,2 \mathrm{D} 3,3 \mathrm{D} 2$ \\
& CS-PG & $4 \mathrm{D} 3$ \\
& Ch4S-PG & 2B6* \\
IV & DS-PG & $2 \mathrm{~B} 6$ \\
& KS-PG & $8 \mathrm{C} 2$ \\
\multirow{2}{*}{ * Following chondroitnase AC II digestion. } \\
\hline
\end{tabular}

membrane, surrounding the neural tube and notochord, and in the ventral portion of the sclerotome (Fig. 2B). Fibrillar staining was also observed in the intersomitic clefts and in the perinotochordal region. However, these PGs were generally absent from regions through which neural crest cells initially will migrate (Fig. 3C,D; Bronner-Fraser, 1986b; Newgreen et al. 1986).

During the course of neural crest cell migration, pattern I CS-PGs increased considerably in extent and 

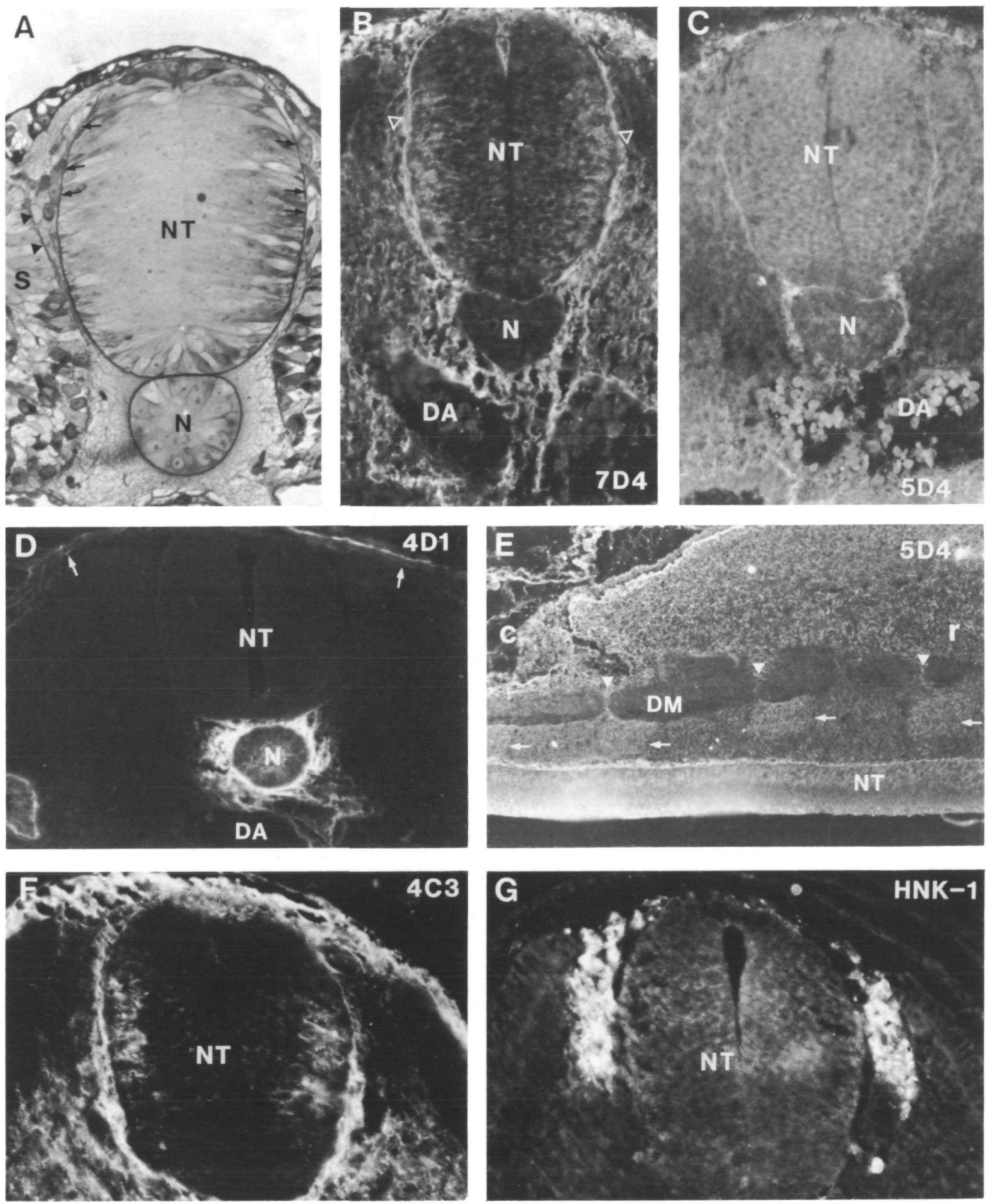

intensity within the sclerotome (Fig. 3A,B). Their deposition appeared to follow a rostral-to-caudal and ventral-to-dorsal sequence, first appearing in the ventral sclerotome concomitant with sclerotome formation and later appearing in the dorsal sclerotome (4-5 somites rostrad). Twelve to fourteen somites rostral to the most recently formed somite, pattern I CS-PGs

were observed throughout the sclerotome. The relative levels of immunoreactivity within the different portions of the sclerotome were quantitated by confocal laser microscopy in conjunction with computerized image analysis. The dorsal sclerotome, containing migrating neural crest cells (Fig. 2F,G) exhibited a 10-fold lower staining intensity for 7D4-immunoreactive CS-PGs 
Fig. 2. Histological and immunofluorescent stainings of transverse and parasagittal sections through the mid-trunk region of embryos during the course of neural crest cell migration (stages 16-18). (A) Transverse section through somite 27 of a stage 16 embryo stained according to the histological procedure of Löfberg and Ahlfors, (1978), which allows optimal retention and visualization of the proteoglycan-rich matrices. Neural crest cells (filled arrow's) emigrating from the dorsal aspect of the neural tube initially proceed along the neural tube (NT) basement membrane. Further ventrally, the neural crest cells also come in contact with the medial surface of the somites (arrowheads). No cells can be seen migrating in the subepidermal space, which is particularly rich in CS/KSPG. Note also the intercellular occurrence of a proteoglycan-containing matrix in the ventral portion of the somites, just prior to segregation of the sclerotome (Courtesy Drs J. Gunnarson and J. Löfberg). $\times 500$. (B) Distribution of CS-PG recognized by the 7D4 mAb (stage 17; somite 25 ; pattern I). Note the extremely weak immunoreactivity in the dorsolateral sclerotome which is occupied by migrating neural crest cells (open arrowheads) when compared with the substantially stronger staining in the ventral portion (Fig. 4, 5) $\times 450$. (C) KS-PG detected by the mAb 5D4 show a faint immunoreactivity within the lateral sclerotome and the periaortic region (pattern I). (D) Distribution of KS-PG reactive with the mAb 4D1 at the level of somite 27 (stage 18; pattern II). Note the delineation of the subepidermal basement membrane (arrows) and the extension of the perinotochordal staining to the supra-aortic region. $\times 350$. (E) Distribution of 5D4reactive KS-PG within the sclerotome of somites 24-27 (stage 18) viewed in the longitudinal plane (parasagittal section). A punctate staining can be noted in the caudal (c) portion of the somites, at the time of neural crest cell migration through the rostral (r) half. Arrowheads mark the levels of the intersomitic clefts. $\times 200$. (F-G) Doublelabelling with mAb 4C3 (F) and the biotinylated HNK-1 antibody detecting neural crest cells at level with somite 19 of a stage 17 embryo $(G)$. Note the paucity in $4 \mathrm{C} 3$ immunolabelling in the area occupied by the migrating neural crest cells. $\times 550 . N=$ notochord; $N T=$ neural tube $\mathrm{DA}=$ dorsal aorta; $\mathrm{DM}=$ dermamyotome.

than did the corresponding ventral sclerotome (Fig. 4B,D). The subepidermal space and neural tube basement membranes exhibited higher levels of immunoreactivity than either the dorsal or ventral sclerotome (Fig. 4A,C). The differences between dorsal and ventral immunoreactivty appeared segmental, being greater at the level of the rostral sclerotome (containing neural crest cells) than at the caudal sclerotome (Fig. 4D,E).

At advanced stages of neural crest cell migration, there was a marked rearrangement of pattern I CS-PG immunoreactivity. Proteoglycan fibrils were observed primarily in the caudal sclerotome, but were absent from the rostral sclerotome in the vicinity of migrating neural crest cells (Figs 3E,F and 4). At final stages of neural crest cell migration and the beginning of their aggregation into peripheral ganglia, pattern I CS-PG fibrils surrounded the ganglia, but were not found within them (Fig. 3G,H).

CS-PGs rich in unsulfated chondroitin (Ch0) chains (recognized by mAb 1B5; pattern II) were detected for the first time during active neural crest cell migration, where they appeared confined to the notochord and its adjacent fibrillar matrix. Similarly, CS-PGs recognized by $\mathrm{mAb} 4 \mathrm{D} 3$ and $\mathrm{CS}-\mathrm{PG}$ s rich in $\mathrm{Ch} 4 \mathrm{~S}$ chains ( $\mathrm{mAb}$ 2B6; pattern III) were observed around the notochord and ventrolateral subepidermal space, but were absent from all other regions of the embryo.

\section{Following gangliogenesis (stages 21-23)}

After neural crest cells had aggregated to form peripheral ganglia, pattern I CS-PGs displayed a metameric arrangement related to the position of the peripheral ganglia. Between adjacent ganglia, these CSPGs were distributed uniformly throughout the lateral sclerotome, including the perinotochordal region. In contrast, the ganglia and the ventral roots, containing axons and neural crest-derived Schwann cells, were devoid of pattern I CS-PGs (Fig. 5A). CS-PGs carrying predominantly $\mathrm{Ch} 6 \mathrm{~S}$ chains (mAb 3B3) persisted in their colocalization with $\mathrm{CS}-\mathrm{PGs}$ detected by mAbs 7D4/6C3/4C3 (Fig. 5B), with the exception of the lateral subepidermal space and the sclerotome adjacent to the neural tube where the latter PGs were absent. Ch6S-PGs were distributed metamerically in the ventral portion of the embryo, within perinotochordal matrix fibrils extending well into the sclerotome between adjacent ganglia at sites of prospective vertebral arch formation (Fig. 5B). No immunoreactivity was observed in the sympathetic ganglia or in the regions of the presumptive adrenal medulla, splanchnic sympathetic plexus and mesenteric ganglia.

Pattern III CS-PGs recognized by mAb 4D3 were concentrated in the subepidermal space, the sclerotome surrounding the neural tube (including its basement membrane) and the perinotochordal region. Between adjacent ganglia, pattern III CS-PGs formed a dense fibrillar network, continuous with that surrounding the notochord and neural tube, and extending ventrally between the notochord and dorsal aorta in prospective regions of vertebral arch formation.

The distribution of CS-PGs bearing predominantly Ch4S (pattern III; mAb 2B6 in conjunction with chondroitinase $\mathrm{AC}$ II digestion) was metameric along the rostrocaudal extent of the sclerotome (Fig. 5C,D), with immunoreactivity enriched between adjacent ganglia in the region of the prospective vertebral arches. Ch0-PGs (pattern II; recognized by mAb 1B5) were solely observed around the notochord. Both Ch0 and Ch4S-bearing CS-PGs were absent from the most dorsal regions of the embryo and the sclerotome ventral to the notochord.

Chondroitinase $\mathrm{ABC} / \mathrm{AC}$ II digestion of the sections prior to application of the mAbs 7D4, 4C3, 6C3 and 4D3 entirely abolished staining, demonstrating that the antibodies reacted exclusively with native CS chains of tissue proteoglycans. In contrast, if the chondroitinase $\mathrm{ABC} / \mathrm{AC}$ II digestion was omitted prior to staining with antibodies 3B3 (Ch6S), 1B5 (Ch0) and 2B6 (Ch4S), no immunoreactivity was observed, which confirmed the specificity of the staining with these antibodies for 

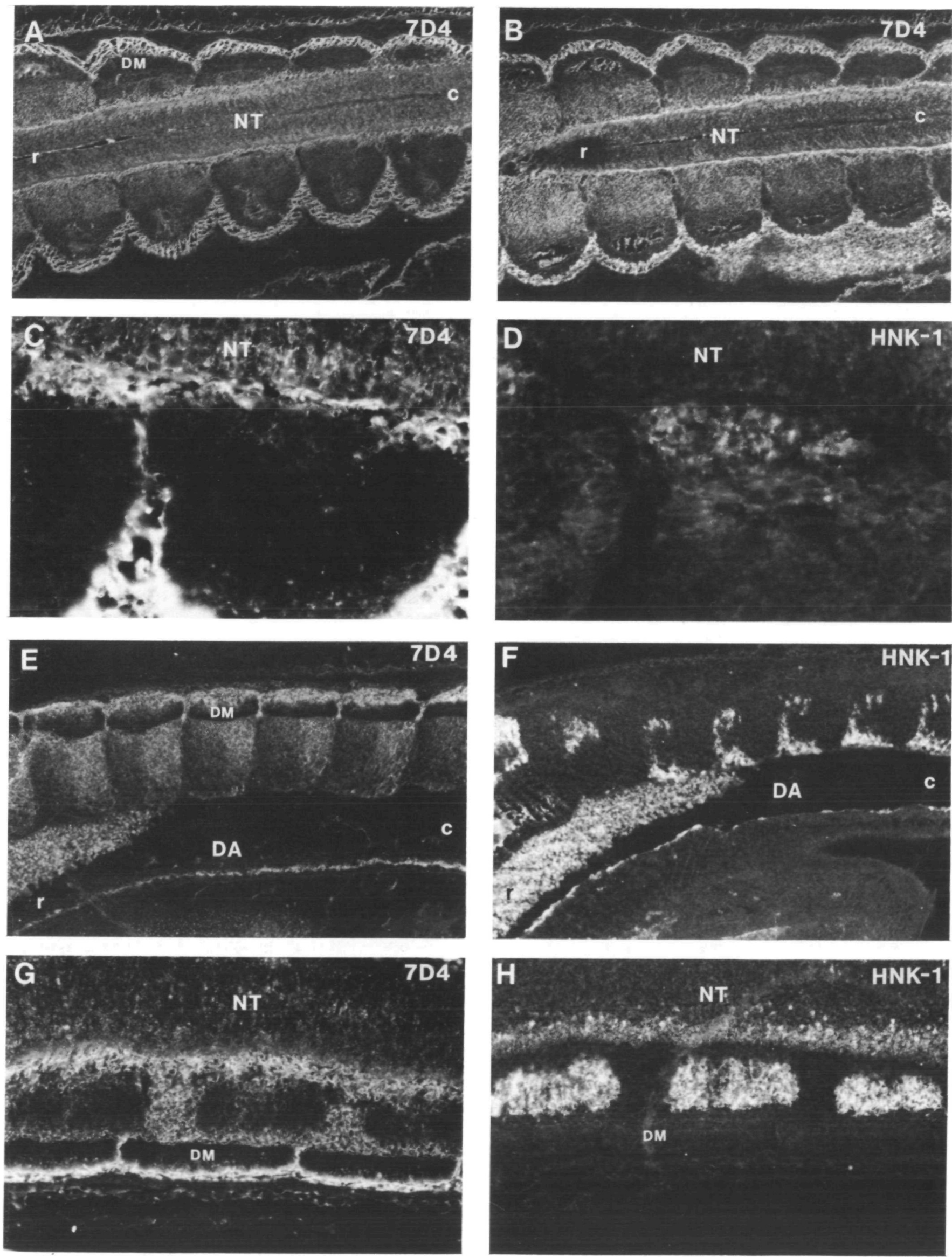
Fig. 3. Parasagittal and transverse sections through embryos at stages of advanced neural crest cell migration (stages 17-18) showing the representative distribution of 7D4-reactive proteoglycans (pattern I) in relation to migrating neural crest cells (identified by the HNK-1 antibody). (A,B) Sclerotomal distribution of 7D4-reactive proteoglycans in the dorsal-ventral dimension. A shows staining in the most dorsal regions of somites $23-27$, whereas the section in $\mathrm{B}$ shows the comparable 7D4 immunolabelling $50-70 \mu \mathrm{m}$ further ventrally. Note also the rostral to caudal $(r-c)$ sequence of expressional to caudal $(\mathrm{r}-\mathrm{c})$ sequence of expression of 7D4-reactive proteoglycans within the somites. $\times 200$. (C,D) High magnification photographs illustrating a double-labelling with mAb 7D4 and the biotinylated HNK-1 (binding of the latter antibody was detected by incubation with streptavidin-Texas Red) of somite 28 and 29 in the horizontal plane. No 7D4 immunoreactivity can be seen ahead of the neural crest cells (D), just about to enter the dorsal, rostral portion of the somite. In contrast, the proteoglycans are heavily concentrated in the intersomitic clefts and in the interstitial matrix between neural tube and somites $(C)$, where no neural crest cells are found. $\times 900$. (E,F) Parasagittal sections through the rostral trunk (somites 11-16). There is a progressive rearrangement of the 7D4-reactive proteoglycans from the rostral to the caudal portion of the somites, which seem to occur coincidently with the invasion of the rostral portion by the migrating neural crest cells. $\times 200(\mathrm{G}, \mathrm{H})$ Parallel staining of two adjacent horizontal sections with mAbs 7D4 $(\mathrm{G})$ and HNK-1 $(\mathrm{H})$. Note how 7D4-reactive proteoglycans are secluded from the sclerotomal area of neural crest cell coalescence into peripheral ganglia. $\times 450$.

epitopes generated by such enzymatic treatment (Couchman et al. 1984).

\section{Distribution of dermatan sulfate proteoglycans (DS- $P G s)$}

The distribution of DS-bearing proteoglycans was defined by comparing the staining patterns observed for the mAb 2B6 following either chondroitinase $\mathrm{ABC}$ or chondroitinase AC II pre-digestion. DS-PGs were not immunohistochemically detectable at stages of initial neural crest cell migration. During advanced stages of neural crest cell migration, immunoreactivity for DSPGs was confined to the notochordal basement membrane and its associated fibrillar matrix (pattern III). At postganglionic stages, DS-PG immunoreactivity became more heavily concentrated in the perinotochordal region, and also appeared in the ventral sclerotome, perioaortic region, and subepidermal space. DS-PGs appeared in a metameric pattern similar to that of Ch4S-PGs in the ventral sclerotome at sites of presumptive vertebral arch formation.

\section{Distribution of keratan sulfate proteoglycans (KS-} PGs)

During neural crest cell migration (stages 14-19)

At initial stages of migration, immunoreactivity with the 5D4 antibody (pattern I KS-PGs; Table 2) was similar to that of Ch6S, but was considerably less widespread and weaker in interstitial matrices. In contrast, immunolabelling with the 4D1, 1B4, 2D3, 3D2 (pattern II KS-PGs; Fig. 2C) and 8C2 antibodies (pattern IV KS-PGs) was observed primarily around the notochord, with some discontinuous staining in the subepidermal space for pattern IV KS-PGs.

With progressive neural crest cell migration, the intensity and distribution of pattern I, II, and IV KSPGs increased in a region-specific manner. A punctate staining for pattern I KS-PGs appeared at advanced phases of neural crest cell migration and accompanied the distribution of pattern I CS-PGs. Distribution of pattern I KS-PGs within the sclerotome initially was uniform, but became progressively excluded from the rostral portion during the course of neural crest cell migration (Fig. 2E).

Pattern IV KS-PGs extended throughout the sclerotome, the intersomitic space, the perinotochordal matrix and were sparsely distributed around the neural tube surface (Fig. 5E,F). Deposition of pattern IV KSPGs preceded and was more abundant than that of pattern I KS-PGs. In contrast to pattern I CS-PGs (Fig. 3A,B) which increased in distribution in a ventralto-dorsal sequence, Pattern IV KS-PGs were augmented in a dorsal-to-ventral sequence (Fig. 5E,F) during the course of neural crest development.

Pattern II KS-PGs were heavily concentrated in the perinotochordal and supra-aortic region, and the subectodermal basement membrane (Fig. 2D). In contrast, immunoreactivity for pattern IV KS-PGs was persistently confined to the perinotochordal area.

Following gangliogenesis (stages 21-23)

Immunoreactivity for pattern I KS-PGs increased and largely coincided with that of pattern I CS-PGs in the dorsal regions of the embryo and in the lateral sclerotome (Fig. 5G) at interganglionic levels. However, some differences were noted; for example, these KS-PGs filled the entire subepidermal space and were sparsely distributed in the perinotochordal region and ventral sclerotome at axial levels containing the peripheral ganglia (Fig. 5G). No staining was observed in the sclerotome surrounding the neural tube at any axial level, though immunoreactivity was observed within the neurogenic region and roofplate of the neural tube.

Pattern IV KS-PG immunoreactivity increased at postmigratory stages, and was apparent throughout the lateral sclerotome at all axial levels. These KS-PGs were widespread within the ganglia and ventral roots, and were largely absent from the medial sclerotome and around the neural tube (Fig. $5 \mathrm{H}$ ). To determine whether pattern IV KS-PG immunoreactivity was present on neural crest-derived cells, sections were double-labelled with $\mathrm{mAb} 8 \mathrm{C} 2$ and the $\mathrm{HNK}-1$ antibody. Although $8 \mathrm{C} 2$ staining was present within the ganglia and ventral roots, it appeared distinct from that produced by the HNK-1 antibody. In the ventrolateral sclerotome, pattern IV KS- PGs were concentrated in the area occupied by neural crest cells forming the sympathetic ganglia. Although outlining the dorsal aorta, pattern IV immunoreactivity largely was absent 

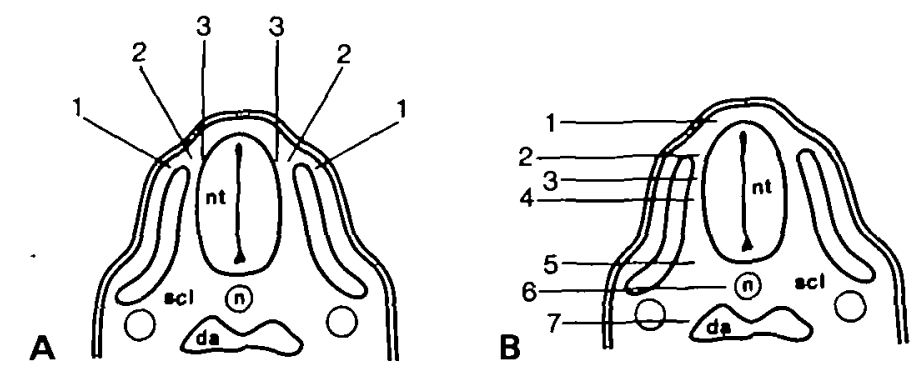

$\square$ aubepidermal apace (1)

[8] neural tube basement mombrane (3)

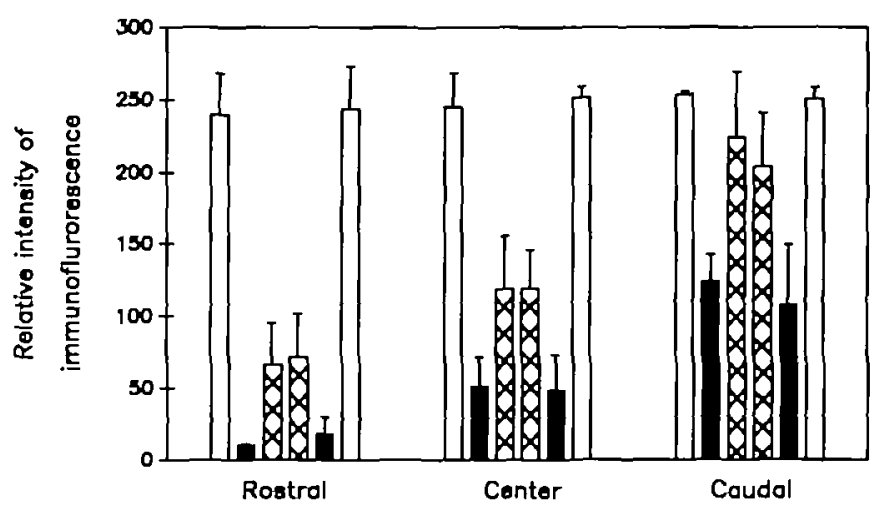

C

Rostro-coudal level through somites

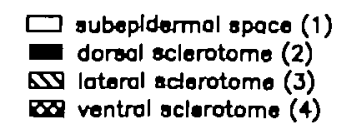

modial sclerotomo (5) DZ perichordal region (8)

[7] perfaortic region (7)



D

Rostro-coudal lovel through somites

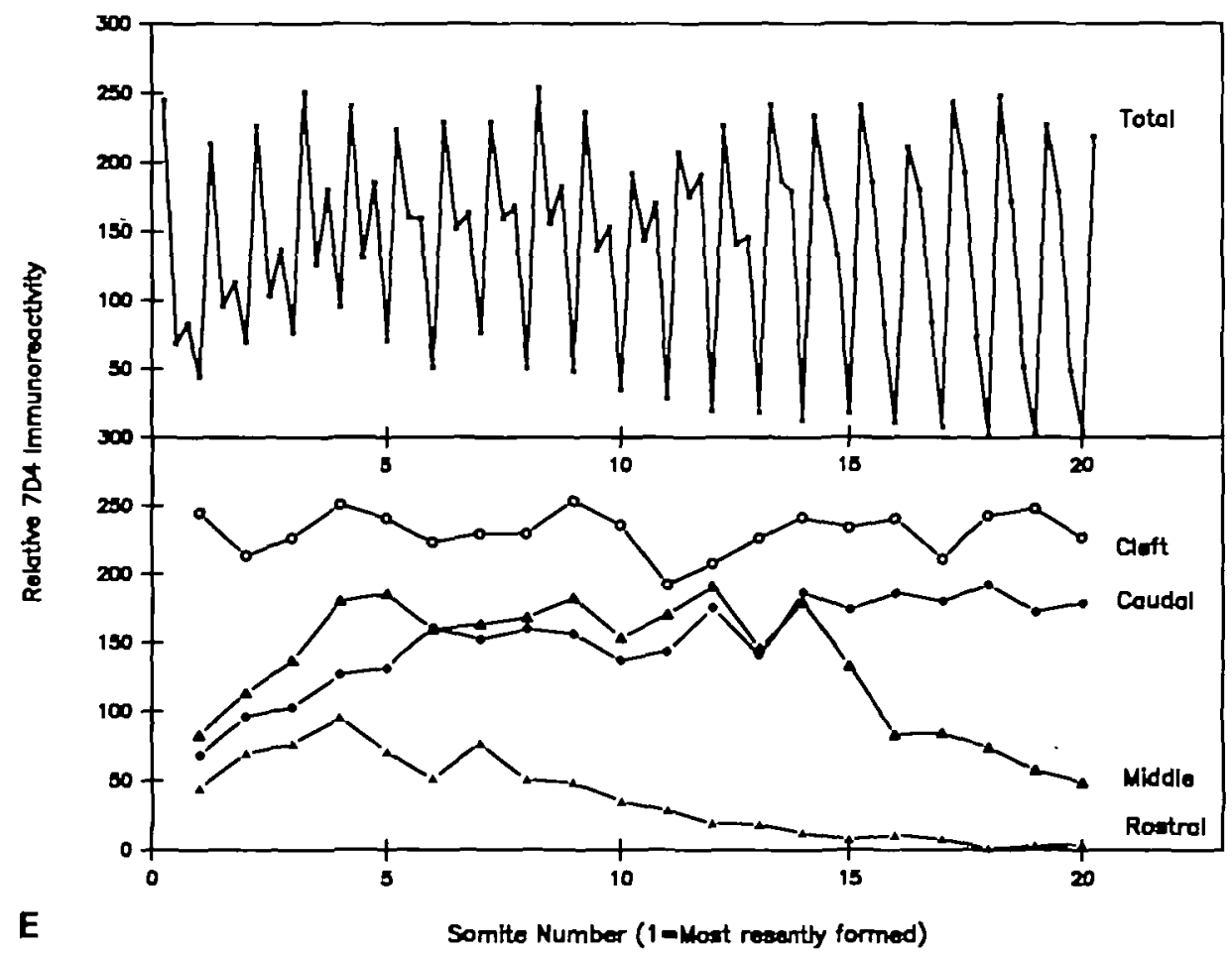

from the peri-aortic region through which adrenomedullary cells and the splanchnic sympathetic plexus precursors move. Pattern IV KS-PGs were pronounced at the sclerotomal-myotomal interface and the notochordal basement membrane.

Pattern II KS-PGs remained concentrated in the 
Fig. 4. Relative measurements of regional immunofluorescent intensities by confocal laser microscopy and computerized image analysis. The intensity levels were estimated by the image analysis program according to an arbitrary scale of $0-255$. (A,B) Diagramatic representation of the measured areas $(1-7)$ in the mediolateral plane (A) and dorsoventral plane (B). (C) Spot measurement of $\mathrm{mAb}$ $4 \mathrm{C} 3$ immunofluorescent intensity across the dorsal portion (medial-lateral plane; see A) of serial transverse sections through somites 17-22 of three different embryos (a total of 74 sections). Bars represent mean values \pm s.D. Rostral, Center and Caudal denote the rostrocaudal level at which the section was cut through the somite. At level rostral, the most advanced neural crest cells were seen level with the perinotochordal area. At level center, the most advanced cells had reached a level corresponding to the middle of the neural tube. At level caudal, only a few neural crest cells could be seen on the dorsolateral aspect of the neural tube. (D) Similar measurements as in $C$, but in dorsoventral plane (see B). (E) Immunofluorescent intensity measurements in the horizontal plane following staining with mAb 7D4. The analysis includes 16 sections from two embryos, each section comprising 20 or more somites. Measurements were carried out within the caudal, middle and rostral portion of each somite and in the intersomitic clefts, starting from the intersomitic cleft of the most recently formed somite (somite 1) and progressing rostrally (end=somite 20 ). The upper panel shows graphically the total fluorescence measurements, starting from the intersomitic cleft between the last and penultimate somite and progressing rostrally. In the lower panel, curves depict the rostrocaudal variations in immunofluorescent intensity in the intersomitic cleft, caudal, medial and rostral portions of the last 20 somites.

perinotochordal space and along the ventral neural tube following ganglion formation. Pattern II KS-PGs also prominently stained the mesonephric tubules and fibrils within the adjacent periaortic sclerotome.

Keratanase (Pseudomonas sp.) and endo- $\beta$-galactosidase (Escherichia freundii) digestion of sections reduced immunoreactivity for mAbs 5D4, 4D1, 1B4, $2 \mathrm{D} 3,8 \mathrm{C} 2$ and $3 \mathrm{D} 2$, indicating that the epitopes recognized by these antibodies were on native $\mathrm{KS}$ chains. At stages of neural crest cell migration, keratanase removed all immunoreactivity for mAbs 5D4, 1B4 and 4D1, whereas some immunoreactivity remained around the notochord after digestion with endo- $\beta$-galactosidase. At postganglionic stages, keratanase and endo- $\beta$-galactosidase treatment completely abolished immunoreactivity for mAb 4D1, but not 5D4. Similarly, some mAb $8 \mathrm{C} 2$ immunoreactivity persisted subepidermally and around the dorsal neural tube after endo- $\beta$-galactosidase, whereas keratanase digestion eliminated all staining. The differential susceptibility to enzymatic degradation indicates that the populations of KS-PGs detected during neural crest cell migration were heterogeneous, carrying unbranched $\mathrm{KS}$ chains with both monosulfated and non-sulfated $N$-acetyllactosamine repeating units (Ito et al. 1986). Interestingly, the differential susceptibility to enzymatic digestion suggested that pattern IV KS-PGs associated with migrating and post-migratory neural crest cells (mAb
$8 \mathrm{C} 2$ ) were abundant in undersulfated $\mathrm{KS}$ chains, whereas those largely absent from the migratory pathways (mAbs 5D4, 4D1 and 3D2) were more heavily sulfated.

\section{Distribution of a heparan sulfate proteoglycan (HS- $P G)$}

At initial neural crest cell migration, immunoreactivity for the mAb 33-2 (pattern IV HS-PG; Table 2) was evident in the all basement membranes surrounding the neural tube and notochord, along the basal side of the epidermis, and on the dorsolateral dermamyotome. In contrast to CS/DS/KS-PGs, no HS-PG staining could be observed in the interstitial matrix. During the course of neural crest cell migration, pattern IV HS-PG immunoreactivity persisted along basement membranes and also became evident within the somitic sclerotome (Fig. 6A). In this region, it occurred in a uniformly arranged fibrillar pattern that accompanied the expression of $\mathrm{CS} / \mathrm{KS}-\mathrm{PG}$ (Fig. 6B). With continued neural crest cell migration through the rostral portion of the somites and subsequent coalescence of the preganglionic cells, HS-PG-containing matrix fibrils became restricted to the ganglia and little or no immunoreactivity could be detected in the surrounding sclerotome.

Following gangliogenesis, HS-PG immunoreactivity was primarily localized in basement membranes, but also occurred in a punctate pattern within the newly formed dorsal root ganglia and surrounding Schwann cells of the ventral roots/rami communicans (Fig. 6C). No staining could be seen within the sympathetic ganglia, the sclerotome surrounding the dorsal root ganglia and notochord, or the periaortic region. The pattern of HS-PG immunoreactivity coincided with that of its potential matrix ligands collagen type IV (Perris et al. 1990a) and laminin (Krotoski et al. 1986). The one exception is that collagen type IV and laminin remain detectable within the sclerotome after gangliogenesis, whereas HS-PG does not remain detectable (Fig. 6C).

\section{Distribution of hyaluronan}

The distribution of hyaluronan was determined by using a specific probe (Knudsen and Toole, 1984; Rippellino et al. 1985) consisting of a biotinylated fragment from the hyaluronan-binding region of the bovine nasal cartilage proteoglycan. At stages of early neural crest cell migration, hyaluronan was found widely distributed along neural crest migratory pathways. This glycosaminoglycan did not appear to be associated with basement membranes, but rather occurred in fibrillar structures apposed to basement membranes. A considerable amount of hyaluronan was seen within the epithelial somites and around the notochord. High levels of staining were detected above the dorsal neural tube in the vicinity of early migrating neural crest cells, particularly along the subepidermal region through which neural crest cells migrate to form melanocytes (Fig. 7A)

During the period of early and advanced neural crest cell migration, abundant amounts of hyaluronan were detected in the ventral regions of the sclerotome. The 

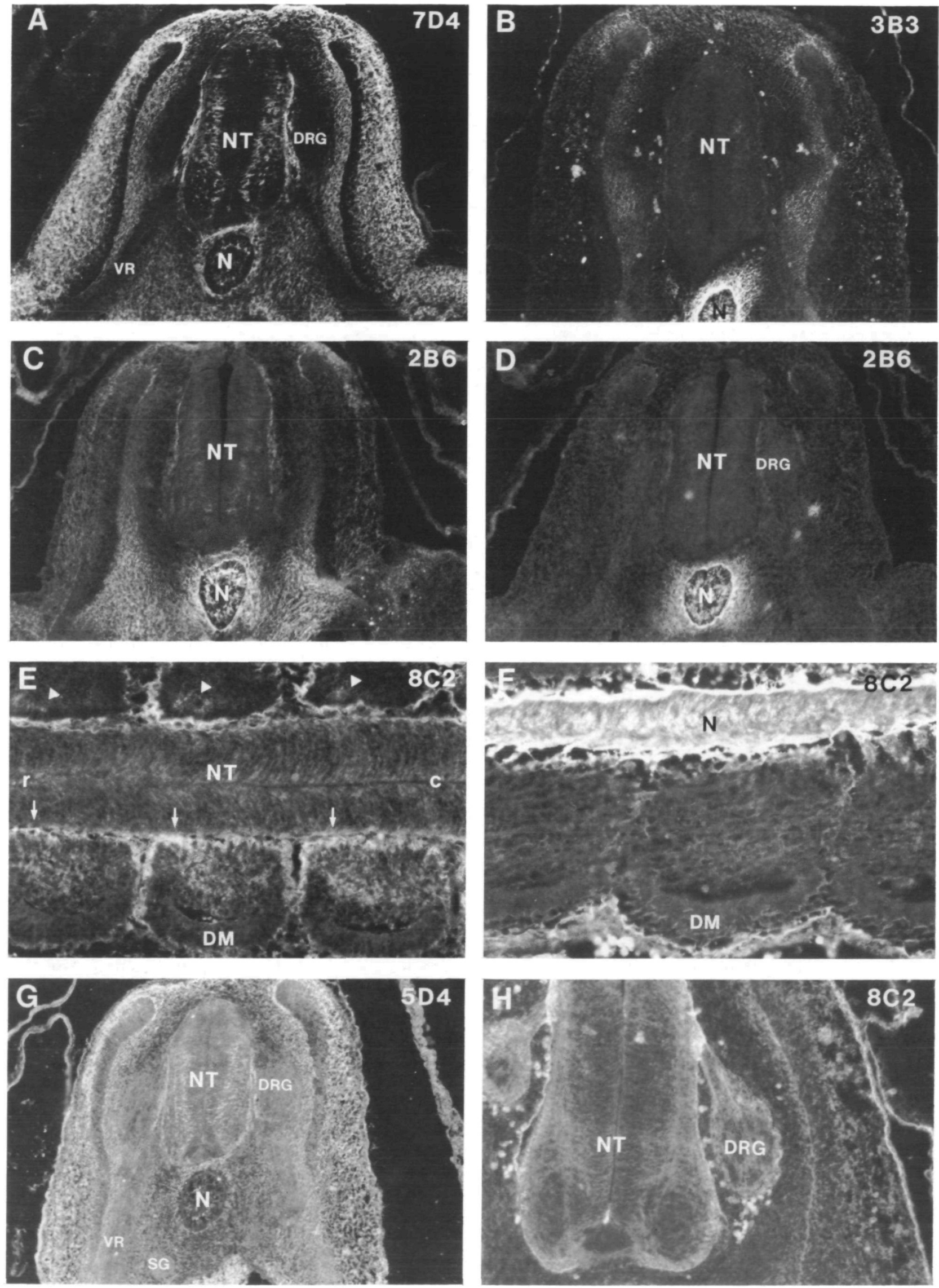
Fig. 5. Distribution of CS-PG and KS-PG at stages of advanced neural crest cell migration (stages 17-18; E,F) and following gangliogenesis (stage 23; A-D,G,H).

(A) Distribution of CS-PG reactive with mAb 7D4 at stages proceeding gangliogenesis at an axial level immediately below the wing bud region (pattern I). Both dorsal root ganglia (DRG) and ventral roots (VR) were enmeshed in a CS-PG-rich matrix, but no immunoreactivity could be seen within these nervous structures.

Immunolabelling was also weak or entirely absent on the dorsolateral aspect of the neural tube. (B) Distribution of Ch6S-PG (mAb 3B3; pattern I) at an axial level caudal of the wing bud region and separating the ganglia (stage 23). Note the lateral restriction of the sclerotomal labelling and the lack of significant immunoreactivity in the lateral subepidermal space. (C,D) Ch4S-PG (mAb 2B6 plus chondroitinase $\mathrm{AC}$ II digestion) at axial levels of the peripheral ganglia (C) and intermediary axial levels corresponding to prechondrogenic sites of vertebra formation (D; stage 23). Both sections run across the wing bud region. $\times 200$. (E) Distribution of KS-PG recognized by $\mathrm{mAb} 8 \mathrm{C} 2$ (pattern IV) during advanced (stages 17-18) in an oblique longitudinal section through the dorsal portion of the neural tube (NT) of a stage 17 embryo (somites 22-25) showing the intrasomitic distribution of $8 \mathrm{C} 2$-reactive KS-PG. These KS-PG were concentrated along the rostral medial surface of the somites (arrows) and were initially localized in the rostral sclerotome (arrowheads). $\times 400$. (F) Longitudinal section of the same truncal region as in $\mathrm{E}$, but cut at the level of the notochord, shows the distribution of $8 \mathrm{C} 2$-reactive $\mathrm{KS}-\mathrm{PG}$ in the ventral portion of the sclerotome. $\times 850$. Note the absence of $8 \mathrm{C} 2$ immunoreactivity within sclerotome.

(G) Distribution of KS-PG recognized by mAb 5D4 at an axial level just above the limb buds (pattern I).

$\mathrm{SG}=$ sympathetic ganglion. $\times 200 .(\mathrm{H})$ Distribution of KSPG recognized by the $8 \mathrm{C} 2$ antibody in a transverse section of a stage 23 embryo ( 7 somites rostral to the limb bud region) showing distribution of this KS-PG following gangliogenesis. In contrast to all other CS/KS-PG, KS-PG recognized by this $\mathrm{mAb}$ were seen within the ganglia. $\times 950$.

hyaluronan density, as evaluated by staining intensity, was greatest adjacent to the notochord and decreased progressively outward into the distal sclerotome. No hyaluronan was detected in the dermamyotome or neural tube (Fig. 7B). Along the rostrocaudal extent of the sclerotome, hyaluronan-rich fibrils were uniformly distributed and extended between, but not across the intersomitic clefts. As neural crest cell migration ceases and gangliogenesis commences, the levels of hyaluronan appeared reduced in the immediate vicinity of neural crest cells. Expression of hyaluronan was weaker in the peripheral ganglia when compared with the strong and uniform interstitial expression observed throughout the sclerotome and subepidermal space (Fig. 7C).

Streptomyces hyaluronidase digestion of the sections prior to application of the probe completely eliminated reactivity. Similarly, inactivation of the probe by oligosaccharide-saturation of its binding site significantly depleted its ability to detect hyaluronan in tissue sections.
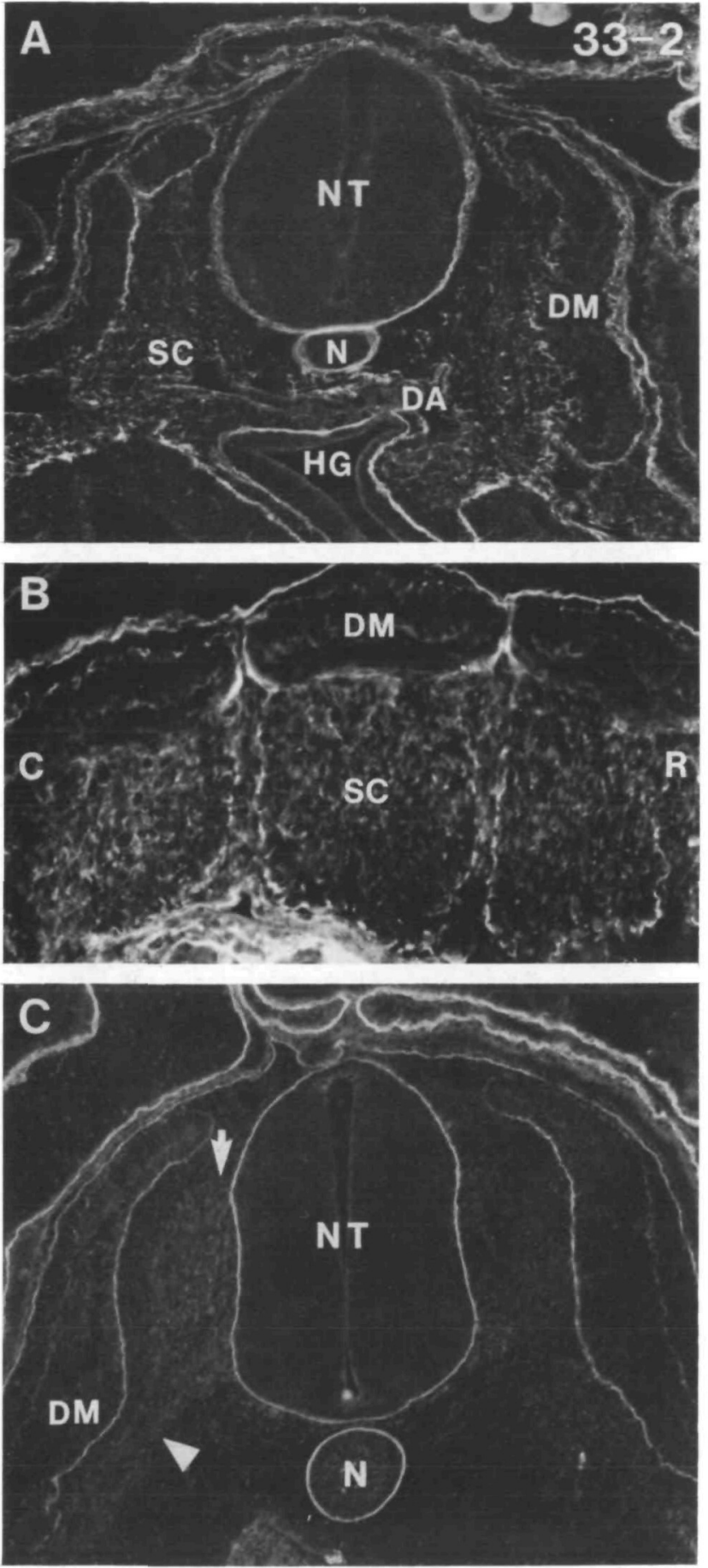

Fig. 6. Immunolocalization of HS-PG detected by the mAb 33-2 (pattern IV) at stages of advanced neural crest cell migration and proceeding gangliogenesis. Distribution of HS-PG in the transverse (A) and parasagittal (B) planes at stages of advanced neural crest cell migration (stage 17). Apart from basement membranes, both matrix molecules also occurred in uniform fibrillar patterns within the sclerotome (SC). (C) Transverse section at stage 22-23 following gangliogenesis. The section is oblique passing through a dorsal root ganglion on one side (left) and at an intersegmental level on the other side. HS-PG was observed within the peripheral ganglia and ventral roots. $\mathrm{R}=$ rostral; $\mathrm{C}=$ caudal; $\mathrm{NT}=$ neural tube; $\mathrm{N}=$ notochord; $\mathrm{DA}=$ descending/dorsal aorta; $\mathrm{HG}=$ hindgut. $\mathrm{A}, \times 200$; $\mathrm{B}, \times 500 ; \mathrm{C}, \times 200$. 

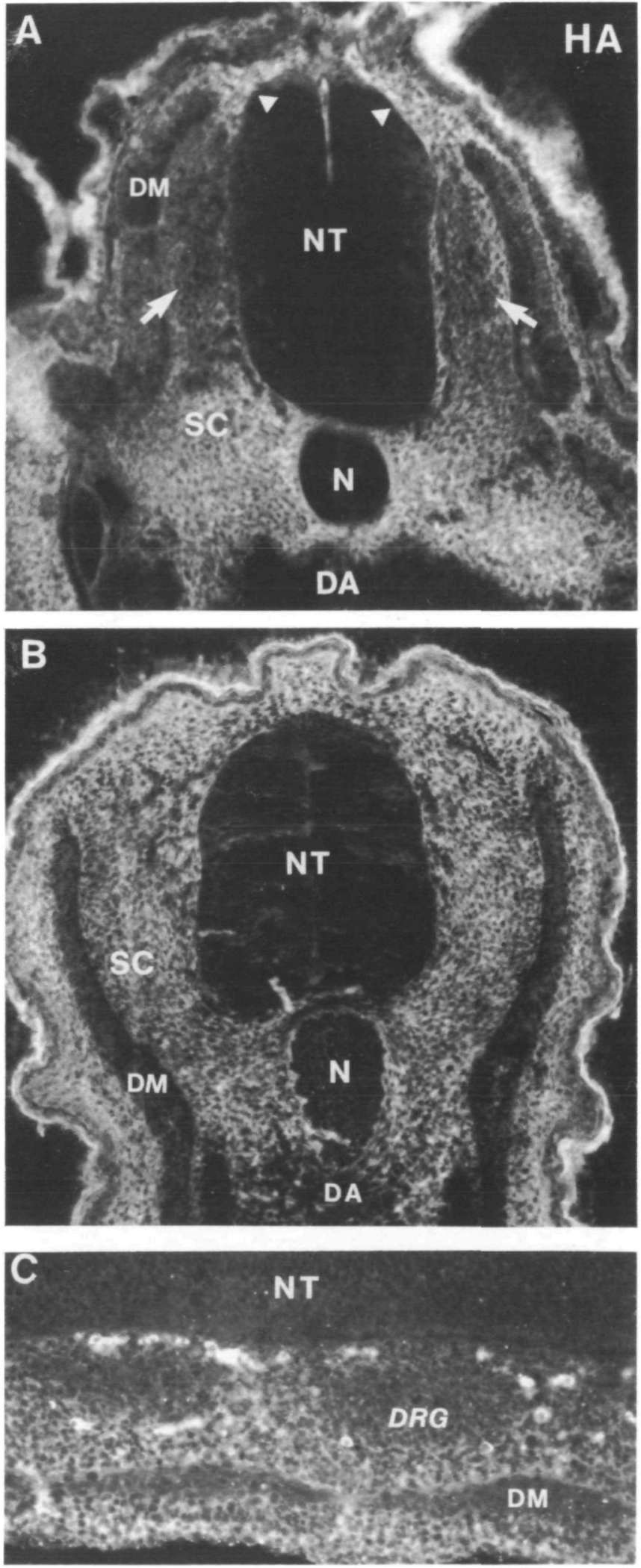

\section{Discussion}

In the present study, the distribution of proteoglycans was related spatially and temporally with the development of avian neural crest cells, by using a panel of
Fig. 7. Sections reacted with the biotinylated hyaluronan probe, followed by incubation with a

streptavidin-fluorescein conjugate, and illustrating the widespread distribution of hyaluronan (HA) in the transverse plane during the course of neural crest cell migration (somite 17; stage 17; A) and in the transverse (B) and parasagittal (C) planes following gangliogenesis (wing bud region, stages 22-23). Note the high levels of (HA) on the dorsolateral aspect of neural tube containing migrating neural crest cells (arrowheads), and the comparatively low expression of (HA) in the sclerotomal region corresponding to the presumptive sites of dorsal root ganglion formation (arrows). However, HA was abundantly distributed in the perinotochordal area, ventral sclerotome and periaortic region, which correspond to the prospective sites of sympathetic ganglion formation and the putative migratory pathway of neuroendocrine precursor cells. (B) Distribution of HA following gangliogenesis (stage 23) at an axial level intersegmental to that of the peripheral ganglia. (C) Distribution of HA viewed in the longitudinal plane (horizontal section) through the sclerotome (stage 20). Note the considerably lower levels of $\mathrm{HA}$ in the dorsal root ganglia (DRG) in comparison with the surrounding sclerotome, and the absence of HA in the neural tube basement membrane. $\mathrm{NT}=$ neural tube; $\mathrm{N}=$ notochord; $\mathrm{SC}=$ sclerotome; $\mathrm{DA}=$ dorsal/descending aorta; DM=dermamyotome. A-B, $\times 200 ; \mathrm{C}, \times 600$.

monoclonal antibodies produced against proteoglycan moieties. Four patterns of immunoreactivity were distinguished by this comparative study: (1) CS/KSPGs rich in Ch6S chains and recognized by $\mathrm{mAb} 7 \mathrm{D} 4$, $6 \mathrm{C} 3,4 \mathrm{C} 3$ and 5D4 were abundantly distributed throughout the embryo during all phases of neural crest development, but were largely absent from the areas occupied by migrating neural crest cells and their derivatives (pattern I); (2) CS/KS-PGs bearing primarily unsulfated chains and recognized by mAbs 4D1, $1 \mathrm{~B} 4,3 \mathrm{D} 2$ and 2D3 consistently were restricted to the perinotochordal region (pattern II); (3) CS/DS-PGs rich in Ch4S chains and recognized by mAbs 4D3 and $2 \mathrm{~B} 6$ were present in the ventral subepidermal space and notochordal region during neural crest cell migration and appeared in areas of presumptive chondrogenesis after the time of gangliogenesis (pattern III); and (4) KS-PGs and an HS-PG, recognized by $8 \mathrm{C} 2$ and $33-2$ antibodies, respectively, that were widely distributed along the migratory pathways during the course of neural crest cell movement, and which later occurred within the structures formed by the neural crest. Hyaluronan was often colocalized with the first set of proteoglycans, but was also prevalent around migrating neural crest cells which seemed to have reduced levels of hyaluronan at postmigratory stages.

The production of a number of monoclonal antibodies with the unique ability to recognize specific moieties of PGs enabled the identification of various classes of PGs in situ. When tested in ELISA, all mAbs were found to react with chick cartilage CS/KS-PGs, as well as with a variety of other species-specific proteoglycans. Further characterization of the antibodies by competitive ELISA and differential enzymatic diges- 
tion demonstrated that mAbs 7D4, 6C3, 4C3 and 4D3 specifically recognized discrete epitopes on native $C S$ chains, whereas mAbs 4D1, 1B4, 2D3, 8C2 and 3D2 reacted with $\mathrm{KS}$ chains of proteoglycans. The specificity of the epitopes recognized by both anti-CS and anti-KS antibodies was shown by their distinguishable affinities for different purified proteoglycans and by their divergent immunochemical properties (Sorrell et al. 1988, 1990; Sorrell and Caterson, 1990). The identity of the epitopes recognized by the anti-KS antibodies was further demonstrated by their differential affinity for keratanase-digested proteoglycan antigens.

Staining of chick embryos during the course of neural crest development with mAbs 7D4, 6C3 and 4C3 yielded strikingly similar patterns. However, this does not necessarily imply that the mAbs recognized the same proteoglycan molecule. The possibility remains that the mAbs may identify distinct proteoglycan classes that colocalize and share common glycosaminoglycan epitopes. Alternatively, the glycosaminoglycan epitopes may reside on different proteoglycan core proteins. Changes in the distribution patterns observed at various phases of development may have reflected developmentally related substitutions of the glycosaminoglycan determinants of the same proteoglycans molecules.

At stages of initial neural crest cell movement, the interstitial matrix around the dorsolateral neural tube and sclerotome contained abundant amounts of hyaluronan, but little or no proteoglycan. Other areas that are rich in a variety of CS/KS-PGs (including the subepidermal space, the area around the ventral neural tube, the notochord and the intersomitic clefts) either entirely lack neural crest cells at early stages of migration (Bronner-Fraser, 1986b; Newgreen et al. 1986) or, in the case of the intersomitic clefts, contain only a minority of neural crest cells (Lallier and Bronner-Fraser, 1988). With progressive neural crest cell migration within the somites and concomittant dispersion of the sclerotomal cells, there was a concomitant increase in the amount of CS/KS-PGs deposited in the interstitial matrix of the sclerotome. This accumulation of PGs appeared following the entrance of neural crest cells, but extended rapidly throughout the sclerotome; thus neural crest cells moved toward embryonic areas dense in proteoglycans.

With progressive migration and the condensation of neural crest cells into peripheral ganglia, the rostral portion of the sclerotome became virtually devoid of $\mathrm{CS} / \mathrm{KS}-\mathrm{PGs}$ (recognized by the mAbs 5D4, 4D1 and 3D2) immunoreactivity. However, some hyaluronan, HS-PG, and KS-PGs, identified by the $8 \mathrm{C} 2 \mathrm{mAb}$, were observed. It is unclear why HS-PG and some forms of KS-PGs are expressed within the peripheral ganglia and ventral roots, but these molecules may have been retained on the cell surface or synthesized by the neural crest-derived neurons and/or glia. The absence of certain CS/KS-PGs from areas occupied by migrating and post-migratory neural crest cells is intriguing in the light of previous reports suggesting that these molecules may inhibit neural crest cell migration. It has been shown that the CS/KS-PGs from bovine nasal cartilage impede neural crest cell locomotion on a number of motility-promoting matrix molecules in vitro (Perris and Johansson, 1987; Perris, 1990; Perris et al. 1990b). The Swarm rat chondrosarcoma proteoglycan and a chick brain proteoglycan also have been found to be nonpermissive for neural crest cell attachment and migration (Newgreen, 1982; Tan et al. 1987). These findings in conjunction with previous in vivo observations in both avians and amphibians (Newgreen et al. 1982, 1986; Tucker, 1986; Tan et al. 1987; Perris et al. $1989 b$; Perris, 1990) suggest that the local assembly of CS/KS-PGs in the matrix may participate in the restriction and cessation of neural crest cell movement. The proteoglycans found to be inhibitory for neural crest cell migration in vitro, such as the bovine nasal cartilage CS/KS-PGs and the chondrosarcoma CSPGs, have a high content of low sulfated chondroitin/ high sulfated keratan and prevalence of Ch4S chains (Heinegård and Paulsson, 1984). Interestingly, we observed that proteoglycans with such characteristics were invariably secluded from the primary migratory pathways of the neural crest. In contrast, there is evidence that $\mathrm{PGs}$ recognized by mAbs $6 \mathrm{C} 3,7 \mathrm{D} 4$, and $4 \mathrm{C} 3$ are oversulfated (Sorrell, unpublished).

Several explanations could account for the low levels of $\mathrm{CS} / \mathrm{KS}-\mathrm{PG}$ immunoreactivity around migrating neural crest cells and their derivatives. Migrating neural crest cells could suppress the secretion and matrix assembly of CS/KS-PGs by the surrounding tissues. Alternatively, neural crest cells and/or adjacent sclerotomal cells could specifically degrade the CS/KS-PGs. A third possibility is that a high rate of hyaluronan shedding from migrating neural crest cells could exclude proteoglycans from the cell surface. High levels of hyaluronan were observed in association with migrating neural crest cells within the dorsolateral sclerotome. It has been suggested that high levels of hyaluronan may be required for the emigration of neural crest cells from neural tubes cultured in the presence of serum CS-PGs (Luckenbill-Edds and Carrington, 1988). Moreover, enhanced hyaluronan synthesis elevates the motility of fibroblasts within collagen gels that contain serum CS-PGs (Chen et al. 1989). We have recently demonstrated that inhibition of neural crest cell migration by CS/KS-PGs requires the close apposition of the proteoglycans with the cell surface, via binding to cell surface hyaluronan (Perris and Johansson, 1990). Thus, in areas sparsely populated with proteoglycans, continuous shedding of hyaluronan from migrating cells may displace proteoglycans from the cell surface, providing a proteoglycanfree microenvironment. In contrast, in regions rich in proteoglycans, such displacement of PGs could be reduced by overwhelming levels of hyaluronan, producing a proteoglycan-rich environment around the cells. Consistent with previous observations (Derby, 1978; Pintar, 1978), we noted that the level of hyaluronan around post-migratory neural crest cells was considerably lower than that around migrating cells. Thus, the balance between extracellular proteoglycans and intra- 
cellular synthesis of hyaluronan may participate in and/or be a consequence of the regulation of neural crest cell migration.

Our findings indicate that a distinct segregation of proteoglycan populations occurs during development, in a fashion that relates to both neural crest cell migration and formation of the axial vertebrae. In the perinotochordal region, CS/KS-PGs recognized by the mAbs 4D3, 4D1, 2B6, 3D2 and rich in $\mathrm{Ch} 4 \mathrm{~S} / \mathrm{Ch} 0$ chains accumulated around the notochord and its surrounding fibrillar network, whereas Ch6S-bearing proteoglycans, CS/KS-PGs reactive with $\mathrm{mAbs} 7 \mathrm{D} 4$ ) $6 C 3 / 4 C 3,8 C 2$ and 5D 4 and HS-PG were considerably less abundant or entirely absent from this region. -However, these latter proteoglycans together with DSPGs were enriched in the dorsal and lateral sclerotome, and in the subectodermal space. The differential occurrence of characteristic cartilage proteoglycans detected by the former antibodies produced a metameric pattern that inversely correlated with ganglion formation and 'prematurely' defined the presumptive chondrogenic sites of vertebral arch formation. In fact, these proteoglycans were restricted to the perinotochordal space and ventral sclerotome at axial levels containing the ganglia, but extended throughout the lateral and dorsal sclerotome at interganglionic levels. The fibrillar network of cartilage-type proteoglycans emanating from the notochord extended to the region of the ventral motor roots (Bronner-Fraser, 1986b).

In conclusion, our comprehensive analysis of the spatial and temporal distribution of proteoglycans indicates that these molecules have differential distribution patterns at times of neural crest migration and that these patterns are modified during development. In several in vivo (Newgreen et al. 1982, 1986; Tucker, 1986; Tan et al. 1987; Perris, 1990; Perris et al. 1990b) and in vitro (Newgreen, 1982; Newgreen et al. 1982; Tan et al. 1987; Perris, 1990; Perris and Johansson, 1987, 1990 ) systems, localized accumulation of proteoglycans correlates with the restriction of neural crest cell migration. Consistent with this, the dorsal subepidermal space is extremely rich in proteoglycans at stages when neural crest cells begin their ventral migration, although neural crest cells do not migrate into the subepidermal region until later stages (Serbedzija et al. 1989). The area around the ventrolateral neural tube, the intersomitic clefts and the perinotochordal region are also particularly densely populated with proteoglycans and these regions also lack migrating neural crest cells. During neural crest cell migration, the caudal sclerotome retains a proteoglycan-rich network, whereas the rostral sclerotome containing neural crest cells loses its proteoglycan-immunoreactivity. Finally, proteoglycans of prevalent cartilage-type accumulate metamerically in subnotochordal and periaortic regions, which are inversely correlated with sites of sympathetic ganglion and aortic plexus formation. Future efforts will be directed toward isolation of region- and age-specific classes of proteoglycans and disturbance of their deposition and/or assembly in situ in order to clarify their roles in neural crest cell migration, gangliogenesis and formation of the axial vertebrae. The use of our immunological probes will facilitate these studies, since these identify specific populations of PGs that have been extracted from tissue.

We thank Drs Bruce Caterson and Douglas Fambrough for providing various antibodies, and $\mathrm{Dr}$ Torward Laurent for donation of the purified proteoglycan fragment. Kristie Bruk, Mary Flowers, and Michael Artinger are thanked for their excellent technical assistance. This study was supported by NIH grant USPHS HD-15527 and the Muscular Dystrophy Association. MB-F is a Sloan Research Fellow.

\section{References}

Bayne, E. K., Anderson, M. J. and Fambrough, D. M. (1984). Extracellular matrix organization in developing muscle: correlation with acetylcholine receptor aggregates. J Cell Biol. 99, 1486-1501.

BronNer-Fraser, M. (1985). Alterations in neural crest migration by a monoclonal antibody that affects cell adhesion. J. Cell Biol 101, 610-617

BronNer-Fraser, M. (1986a). An antibody to a receptor for fibronectin and laminin perturbs cranial neural crest development in vivo. Devl Biol. 117, 528-536.

BronNER-Fraser, M. (1986b). Analysis of the early stages of trunk neural crest migration in avian embryos using monoclonal antibody HNK-1. Devl Bıol. 115, 44-55.

Bronner-Fraser, M. (1988). Distribution and function of tenascin during cranial neural crest development in the chick. $J$. Neurosci. Res. 21, 135-147.

Bronner-Fraser, M. and Lallier, T. (1988). A monoclonal antibody against a laminin-heparan sulfate proteoglycan complex perturbs cranial neural crest migration in vivo. $J$ Cell Biol. 106, 1321-1329.

Caterson, B., Calabro, T. and Hampton, A. (1987). Monoclonal antibodies as probes for elucidating proteoglycan structure and function. Wight TN, Mecham RP (eds). 'Biology of Proteoglycans.' Academic Press, Inc., pp. 1-25.

Chen, J. W. Y., Grant, M. E., Shor, A. M. and Shor, S. L. (1989). Differences between adult and foetal fibroblasts in the regulation of hyaluronate synthesis: correlation with migratory activity. J. Cell Sci. 94, 577-584.

Couchman, J. R., Caterson, B., Christner, J. E. and Baker, J. R. (1984). Mapping by monoclonal antibody detection of glycosaminoglycans in connective tissues. Nature. 307, 650-652.

DERBY, M. A. (1978). Analysis of glycosaminoglycans within the extracellular environments encountered by migrating neural crest cells. Devl Biol. 66, 321-336.

Derby, M A. And Pintar, J. E. (1978). The histochemical specificty of Streptomyces hyaluronidase and chondroltinase ABC. Histochem. J. 10, 529-547.

Heinegard, D. and Paulsson, M. (1984). Structure and metabolism of proteoglycans. In Extracellular Matrix Bıochemistry, K. A. Piez and A. M. Reddi, eds. Plenum Publishung Corp., New York, pp. 277-328.

Ito, M., Hirabayashi, Y. and Yamagata, T. (1986). Substrate specificity of endo- $\beta$-galactosidase from Flavobacterium keratolyticus and Escherichia freundil is different from that of Pseudomonas sp. J. Biochem. 100, 773-780.

KNudSEN C. AND TOOLE, B. P. (1985). Fluorescent morphological probe for hyaluronate. J. Cell Biol. 100, 1753-1758.

Krotoski, D., Domingo, C. and Bronner-Fraser, M. (1986). Distribution of a putative cell surface receptor for fibronectin and lamınin in the avian embryo. J. Cell Biol. 103, 1061-1071.

Kvist, T. N. AND Finnigan, C. V. (1970). The distribution of glycosaminoglycans in the axial region of the developing chick embryo. J. exp. Zool 175, 221-240.

Lallier, T. and Bronner-Fraser, M. (1988). A spatial and temporal analysis of dorsal root and sympathetic ganglion formation in the avian embryo. Devl Biol. 127, 99-112. 
Laurent, U. B. G. and Tengblad, A. (1980). Determination of hyaluronte in biological samples by a specific radioassay technique. Anal. Biochem. 109, 386-394.

LOFBERG, J. AND AhLFoRs, K. (1978). Extracellular matrix organization and early neural crest cell migration in the axolotl embryo. In 'Formshaping movements in Neurogenesis', (eds. C. O. Jacobson and T. Ebendal), pp. 87-101, Almqvist and Wiksell, Int. Stockholm.

LófberG, J., Ahlfors, K. And Fällström, C. (1980). Neural crest cell migration in relation to extracellular matrix organization in the embryonic axolotl trunk. Devl Biol. 75, 148-167.

Lófberg, J., Nynas-McCoy, A., Olsson, C., Jónsson, L. And PERRIS, R. (1985). Stimulation of initial neural crest cell migration by tissue grafts and extracellular matrix transplanted on microcarriers. Devl Biol. 107, 442-459.

Lófberg, J., Perris, R. and Epperlein, H. H. (1989). Timing in the regulation of neural crest cell migration: Retarded 'maturation' of regional extracellular matrix inhibits pigment cell migration in embryos of the white axolotl mutant. Devl Bıol. $131,168-181$.

Luckenbill-Edds, L. and Carrington, J, L. (1988). Effect of hyaluronic acid on the emergence of neural crest cells from the neural tube of quail, Coturnix coturnix japonica. Cell Tissue Res. 252, 573-579.

Mehmet, R., Scudder, P., Tang, P. W., Hounsell, E. F., Caterson, B. and Feizi, T. (1986). The antigenic determinants recognized by three monoclonal antibodies to $\mathrm{KS}$ involve sulphated hepta- or larger oligosaccharides of the poly $(\mathrm{N}$ acetyllactosamine) series. Eur. J. Blochem. 157, 385-391.

Morriss-KAY, G. AND TUCKETT, F. (1989). Immunohistochemical localization of chondroitin sulfate proteoglycans and the effect of chondroitınase $\mathrm{ABC}$ in 9- to 11-day rat embryos Development 106, 787-798.

NewgreEN, D. F. (1982). Adhesion to extracellular materials by neural crest cells at stage of initial migration. Cell Tissue Res. 227, 297-317.

Newgreen, D. F. and Erickson, C. A. (1986). The migration of neural crest cells. Int. Rev. Cytol. 103, 89-145.

Newgreen, D. F., Gibbins, I. L., Sauter, J. Wallenfels, S. B. AND WUTZ, R. (1982). Ultrastructural and tissue-culture studies on the role of fibronectin, collagen and glycosammoglycans in the migration of neural crest cells in the fowl embryo. Cell Tissue Res. 221, 521-549.

Newgreen, D. F., Scheel, M. and Kastner, V. (1986). Morphogenesis of sclerotome and neural crest in avian embryos: in vivo and in vitro studies on the role of notochordal extracellular matrix. Cell Tissue Res. 244, 299-313.

Newgreen, D. F., Powell, M. E. and Moser, E. (1990). Spatiotemporal changes in HNK-1/L2 glycoconjugates on avian embryo somite and neural crest. Devl Biol. 139, 100-120.

Oegema, T. L., Hascall, V. C. and Dziewiatkowski, D. (1975) Isolation and characterization of proteoglycans from the Swarm rat chondrosarcoma. J. biol. Chem. 250, 6151-6159.

PerRIS, R. (1990). Role of proteoglycans in neural crest development. Trends in Glycosci. Glycotech. (in press).

Perris, R., Lofberg, J., Fällstrom, C., von Boxberg. Y. and NewgreEN, D. F. (1990b). Structural and compositional divergences in the extracellular matrix encountered by neural crest cells of the white mutant axolotl embryo. Development. 109, 533-551.

Perris, R. and Bronner-Fraser, M. (1989). Recent advances in defining the role of the extracellular matrix. Comm. Devel. Neurobiol. 1(1) 61-87.

Perris, R. And Johansson, S. (1987). Amphibian neural crest cell migration on purified extracellular matrix components: a chondroitin sulfate proteoglycan inhibits locomotion on fibronectin substrates. J. Cell Biol. 105, 2511-2522.

Perris, R. and Johansson, S. (1990). Inhibition of neural crest cell migration by aggregating chondroitin sulfate proteoglycans is mediated by their hyaluronan-binding region. Devl Bıol. 137, 1-12.

Perris, R. Paulsson, M. and Bronner-Fraser, M. (1989). Molecular mechanisms of neural crest cell migration on fibronectin and laminin. Devl Biol. 136, 222-238.

Perris, R., Krotoski, D. and Bronner-Fraser, M. (1990a). Collagens in neural crest development: distribution in vivo and motility-promoting activity in vitro. Submitted.

Pintar, J. E. (1978). Distribution and synthesis of glycosaminoglycans during quail neural crest morphogenesis. Devl Biol. 67, 444-464.

Ripelino, J. A., Klinger, M. M., Margolis, R. U. and Margolis, R. K. (1985). The hyaluronic acid binding region as a specific probe for the localization of hyaluronic acid in tissue sections. J. Histochem. Cytochem. 33, 1060-1066.

Serbedzija, G., Bronner-Fraser, M. and Fraser, S. E. (1989) Vital dye analysis of the timing and pathways of avian trunk neural crest cell migration. Development 106, 806-816.

Sorrell, J. M. and Caterson, B. (1990). Monoclonal antibodies specific for keratan sulfate detect epithelial-associated carbohydrates. Histochemistry 94, 269-277.

Sorrell, J. M., Mahmoodian, F. and Caterson, B. (1988). Immunochemical and biochemical comparisons between embryonic chick bone marrow and epiphysial cartilage chondroitin/dermatan sulfate proteoglycans. J. Cell Sci. 91, 81-90.

Sorrell, J. M., Mahmoodian, F., Schafer, I. A., Davis, B. And Caterson, B. (1990). Identification of monoclonal antibodies that recognize novel epitopes in native chondroitın/dermatan sulfate glycosaminoglycan channs: their use in mapping functionally distinct domains of the human skin. $J$. Histochem. Cytochem. 38, 393-402

Tan, S. S., Crossin, K. L., Hoffman, S. and Edelman, G. M. (1987). Asymmetric expressin in somites of cytotactin and its proteoglycan ligand is correlated with neural crest cell distribution. Proc. natn. Acad Sci. U.S A. 84, 7977-7981.

TENGBlad, A. (1979). Affinity chromatography on immobilized hyaluronate and its application to the isolation of hyaluronatebinding proteins from cartilage. Biochum. bıophys. Acta 578 281-289.

TUCKER, R. P. (1986). The role of glycosaminoglycans in anuran pigment cell migration. J. Embryol. exp. Morph. 92, 145-164.

(Accepted 23 November 1990) 